This is the last working paper version of an article that was published in the International Economic Review 2014, 55(1), p.197-222.

\title{
Exit Options and Dividend Policy under Liquidity Constraints*
}

\author{
Pauli Murto \\ Marko Terviö \\ Aalto University and HECER \\ Aalto University and HECER
}

February, 2013

\begin{abstract}
We introduce a post-entry liquidity constraint to the standard model of a firm with serially correlated profitability and an irreversible exit decision. We assume that firms with no cash holdings and negative cash flow must either exit or raise new cash at a transaction cost. This creates a precautionary motive for holding cash, which must be traded off against the liquidity cost of holding cash. We characterize the optimal exit and payout policy. The direct effect of financial frictions is to impose inefficient exit, but there is also an indirect effect through higher equilibrium price which leads to inefficient survival. (D81, D92, G35)
\end{abstract}

\footnotetext{
${ }^{*}$ We thank the Editor, two anonymous referees, Richard Friberg, Chris Hennessy, Mitri Kitti, Niku Määttänen, Juuso Välimäki, Johan Walden, and numerous seminar audiences for helpful comments, and Jia Yu for excellent research assistance. Murto thanks the Academy of Finland and Terviö thanks the OpenLink Fund at the Coleman Fung Risk Management Research Center at UC Berkeley and the European Research Council (ERC Grant Agreement n. 240970) for financial support.
} 


\section{Introduction}

We analyze how financial frictions affect the optimal policy and survival prospects of a firm that operates under persistent cash flow uncertainty. The persistence in profitability implies that a firm should exit if the current cash flow falls sufficiently low. Financial frictions imply that a firm may also exit due to insufficient liquidity even when continuation would be economically efficient. Our model captures the interaction of these two dimensions - profitability and liquidity - underlying firm exit, and shows how the firm should optimally manage its cash reserves to cope with the liquidity constraint. The solution is a policy for exit and payouts that depends on the current levels of both profitability and cash holdings. We also analyze the associated steady state distribution of firms in a competitive industry, and show how it can involve either too much or too little exit, the latter case being a type of "survival of the fattest."

Our starting point is a standard real option model of a firm with serially correlated profitability and an irreversible exit decision. ${ }^{1}$ In this setup the potential for future profits and the irreversibility of exit make it optimal for a firm to continue even when facing expected losses. Cash holdings are irrelevant in the absence of financial constraints and the optimal policy is simply a negative threshold level of profitability below which the firm exits. The optimal exit policy thus requires the ability to sustain negative cash flows indefinitely. It seems realistic in many contexts that a firm with a long history of losses would find it difficult to keep raising more funds. But as soon as there is a limit to a firm's ability to sustain losses the firm's problem changes in a fundamental way.

In our basic case we model the liquidity constraint as the complete inability to raise new funds. The firm has an initial stock of cash that can only be augmented with retained earnings. A firm without cash and with a negative cash flow is forced to exit immediately regardless of its future prospects, so firms have an incentive to hoard cash in order to avoid inefficient exit in the future. This precautionary saving is costly due to the liquidity premium: cash holdings earn interest at a rate below the discount rate. Therefore, if the firm is sufficiently safe from forced exit-with a sufficiently benign combination of cash flow and cash holdings - it is strictly optimal to pay out some of the cash to the owners. Thus, besides affecting the optimal exit policy, the model

\footnotetext{
${ }^{1}$ See e.g. Chapter 7 in Dixit and Pindyck (1994).
} 
also generates the optimal dividend policy. At the same time, if the firm is currently unprofitable and the remaining cash holdings are relatively small, it can be optimal to pay out the remaining cash and close down operations rather than run the risk of forced exit later on. We call this feature of the optimal policy "precautionary exit." We characterize the optimal policy and analyze its dependence on the properties of the cash flow process. Our model leads to a free boundary partial differential equation problem that does not have an analytical solution. Instead of attempting to solve the firm's problem directly we formulate it as a recursive dynamic programming problem and show how it can be easily solved by value function iteration. The solution has an intuitive interpretation and we illustrate its comparative statics properties graphically. Our numerical results show that even a small liquidity premium has a large impact on optimal firm behavior.

We do not explicitly model the causes behind the liquidity constraint. One natural cause is asymmetric information: it can be difficult for a firm or a manager to credibly convey to investors the potential for profits. ${ }^{2}$ Aside from the liquidity constraint, our model has no other imperfections such as agency problems.

The literal interpretation of the decision-maker in our basic model is a risk neutral owner-entrepreneur who can increase cash holdings only through retained earnings. Nevertheless, we believe our findings have relevance in the wider context. In an extension we show that our results are robust to allowing the owners to raise new funds at a transaction cost; in effect the basic model assumes that this cost is prohibitive.

We also analyze the impact of the liquidity constraint at the level of an industry. Our concept of competitive industry equilibrium with entry and exit of firms is essentially that of Hopenhayn (1992), and we assume that the uncertainty faced by individual firms is due to idiosyncratic productivity shocks. In this setup the liquidity constraint causes an obvious overselectivity effect in terms of productivity: some marginally productive firms that should survive a temporary loss exit due to insufficient funds (or, more accurately, in order to preempt forced exit). This effect tends to make the remaining industry on average more productive by weeding out marginally

\footnotetext{
${ }^{2}$ For evidence on the importance of liquidity constraints for firms, see, for example, Evans and Jovanovic (1989), Holtz-Eakin, Joulfaian and Rosen (1994), and Zingales (1998). There is also a literature on endogenous borrowing constraints, e.g., Albuquerque and Hopenhayn (2004), and DeMarzo and Sannikov (2006). Holmström and Tirole (2011, esp. Chapters 1-2) discuss why agency problems may cause a firm to face a liquidity constraint.
} 
productive firms that would need financing to survive. However, the liquidity constraint also induces some formerly productive firms with sufficient cash holdings to stay on even when their productivity falls below the socially efficient exit threshold. This is a type of "survival of the fattest" as coined by Zingales (1998). As a result of these counteracting effects, the liquidity constraint may either reduce or increase the average productivity of firms. In a calibrated example, we find that the former effect dominates as the liquidity constraint increases average productivity by $3.6 \%$. The welfare loss due to the liquidity constraint shows up as a consumer price that is higher by $7.3 \%$.

\section{Related literature}

Our model builds on elements from the literature on the optimal exercise of options, where the seminal papers are by McDonald and Siegel (1986), who model the optimal timing of investment under uncertain cash flow, and by Dixit (1989), who analyzes the firm's optimal entry and exit decisions in the same framework. A large number of extensions to various directions is summarized by Dixit and Pindyck (1994). Our paper extends this line of research to another direction by adding a liquidity constraint that may prevent the firm from covering operating losses.

One paper that addresses the effects of liquidity constraints on the optimal exercise of real options is by Boyle and Guthrie (2003), who analyze the optimal timing of investment when uncertain wealth prior to the investment affects the firm's ability to finance the investment. Our paper, by contrast, focuses on post-investment uncertainty and its effects on optimal payouts and exit.

A special case of our model, where we assume away the liquidity premium, bears close resemblance to the problem of a financially constrained firm in Mello and Parsons (2000), who analyze the optimal hedging policy for a firm that faces persistent cash flow risk and cannot raise new funds. Gryglewicz (2011) presents a model of a financially constrained start-up firm, where the mean level of a stochastic cash flow is learned over time. Eventually, as firms mature, they either go bankrupt, or their confidence of being high type converges to certainty, in which case they face only i.i.d. risk and their cash holdings increase without limit. In these models the firm has to choose the optimal exit policy, but it has no reason to ever pay out dividends.

It is important to make a clear distinction between our model and an ostensibly 
similar stream of literature that considers the problem of a liquidity constrained firm under non-persistent cash flow risk. This other literature models cumulative earnings as a Markovian stochastic process, which leads to independently distributed earnings across periods, whereas we model the level of earnings as the state variable which results in serially correlated earnings. Milne and Robertson (1996) is a representative model of a firm facing a memoryless profit stream under a financial constraint, where the firm faces exogenous liquidation if cash balance falls below a given threshold. The optimal policy is to accumulate a buffer stock of savings up to a point and pay out as dividends all income above that level. A number of other papers analyze various additional features in a similar framework: Radner and Shepp (1996) and Dutta and Radner (1999) add an operation policy that controls risk-return properties of the earnings process, Décamps and Villeneuve (2007) analyze the optimal exercise of a growth option, Peura and Keppo (2006) introduce a delay time to recapitalization, and Rochet and Villeneuve (2005) allow flexible allocation of reserves in risky and safe alternatives. Décamps, Mariotti, Rochet, and Villeneuve (2011) assume costly recapitalization, and analyze the implications of such financing frictions on the firm's cash management and stock price dynamics.

The attraction of modeling the level of profits as a memoryless process is that it results in one-dimensional state-space, which yields analytical solutions. The drawback is that the liquidity constraint is then the only reason why the firm would ever exit, because the future always looks equally profitable. This is reasonable for a firm that consists of financial assets whose prices react to news in an efficient market but is less suited as a model of a firm facing uncertainty over real (non-financial) operations. In our setup, the firm's profitability (the level of expected profit flow) fluctuates, making entry and exit natural features of the economy irrespective of whether there are liquidity constraints or not. Having a first-best benchmark that involves firm exit allows us to analyze how the liquidity constraint affects firm survival, and how, at industry level, it impacts firm selection.

There are also a few papers on the macroeconomic effects of financial frictions that are related to ours. Cooley and Quadrini (2001), Gomes (2001), and Jones (2003) use as building blocks models of firm dynamics with serially correlated productivity. In Gomes's and Jones's papers firms also face an exit decision, and in the latter paper the financial constraint may force the firm to exit in states where it would be socially efficient to continue. However, due to different focus, none of these papers 
characterize the joint exit-payout policy of the firm.

Our setup is also related to the models of precautionary saving. The seminal papers on precautionary saving by Zeldes (1989) and Deaton (1991) analyze the problem of optimal lifetime consumption. Under serially correlated income shocks the state space is two-dimensional (savings and expected income) as in our model; the key difference is that consumers do not face an exit decision. For consumers, precautionary saving results from the convexity of marginal utility, whereas in our model it results from the threat of forced exit.

Next we characterize the problem of the firm. We begin with the basic model, where the firm cannot raise outside funds, and then add the possibility of raising cash at a transaction cost. In section 3 we solve the firm's optimal policy. In section 4 we analyze the implications of the liquidity constraint for a competitive industry and present a calibrated example.

\section{The Problem of the Firm}

The firm faces a stochastic revenue flow $x_{t}$ that follows geometric Brownian motion

$$
d x_{t}=\mu x_{t} d t+\sigma x_{t} d w_{t}
$$

where $d w_{t}$ is the increment of a standardized Wiener process (i.e., with mean zero and variance $d t$ ). The firm earns a profit flow $\pi_{t}=x_{t}-c$ where the fixed cost $c$ is a positive constant. Exit is irreversible and without an additional exit cost or scrap value. (The entry decision will only show up in industry equilibrium.) The objective is to maximize the expected present value of the income to the owners, discounted at rate $\rho>\mu$.

There are two fundamentally different cases. An unconstrained firm can accumulate negative profits indefinitely if needed. The problem of an unconstrained firm is described by the standard real option model of optimal exit. The sole decision is to choose the exit threshold for $x_{t}$, so there is no meaningful decision for when (if at all) to retain cash or pay dividends.

A constrained firm has to worry about its ability to cover negative profits using its existing cash reserves. The optimal exit policy depends both on revenue $x_{t}$ and cash holdings $s_{t}$. The firm's cash holdings are augmented by the profit flow and by

the interest earned on the cash holdings at an exogenous rate $r \leq \rho$. The difference 
$\rho-r$ is the liquidity premium. If $r<\rho$ then the cash held inside the firm incurs a cost to the owners, so they face a meaningful decision of how to pay dividends. ${ }^{3}$ The downside of payouts is that reduced cash holdings lower the capability to cover any future losses. We start by assuming that the liquidity constraint is very stark in the sense that it is not possible to inject more cash into the firm. In this case the firm is forced to exit if it has no cash while facing a negative cash flow. We later extend the model to the case where new funds may be raised at some transaction cost; the basic version can be thought of as a special case in which such transaction costs are prohibitive.

\subsection{Unconstrained Firm}

The unconstrained firm will exit if the cash flow becomes too negative. The value function $V^{*}(x)$ gives the expected discounted future cash flows for a firm with current revenue level $x_{t}=x$, and it is defined by the familiar differential equation:

$$
\rho V^{*}(x)=x-c+\mu x V_{x}^{*}(x)+\frac{\sigma^{2}}{2} x^{2} V_{x x}^{*}(x)
$$

(see e.g. Dixit and Pindyck 1994, Chapter 7) with the constraints that $V_{x}^{*}$ be continuous ("smooth pasting") and have a finite limit. This ODE has a well-known closed-form solution. The firm exits when $x_{t}$ falls to $x^{*}$ given by

$$
\begin{aligned}
x^{*} & =\frac{\beta(\rho-\mu)}{\beta-1} \frac{c}{\rho}, \\
\text { where } \beta & =\frac{1}{2}-\frac{\mu}{\sigma^{2}}-\sqrt{\left(\frac{\mu}{\sigma^{2}}-\frac{1}{2}\right)^{2}+\frac{2 \rho}{\sigma^{2}}}<0 .
\end{aligned}
$$

The unconstrained value function is

$$
V^{*}(x)=\left\{\begin{array}{cc}
\left(\frac{c}{\rho}-\frac{x^{*}}{\rho-\mu}\right)\left(\frac{x}{x^{*}}\right)^{\beta}+\frac{x}{\rho-\mu}-\frac{c}{\rho} & \text { for } x \geq x^{*} \\
0 & \text { for } x<x^{*}
\end{array}\right.
$$

\section{$2.2 \quad$ Fully Constrained Firm}

The constrained firm has an initial cash balance $s_{0}$ that is exogenous to the problem. Cash earns interest at rate $r \leq \rho$. At any moment $t$, the firm can run down its cash

\footnotetext{
${ }^{3}$ Another literal interpretation is that the owner-manager is risk neutral but discounts consumption by more than the return on cash. Decamps et al (2008) interpret $\rho-r$ as a reduced form of an agency cost, caused by the manager engaging in wasteful activities with the firm's liquid assets.
} 
balance by paying dividends. Paying dividends is costless and instantaneous. The objective of the firm is to maximize the expected discounted stream of dividend payments. We denote by $D:=\left\{D_{t}\right\}_{t \geq 0}$ the cumulative dividend process. The restrictions that we impose on this process are the following. First, since we allow only positive dividend payments, the process must be increasing. Second, the dividend payment $d D_{t}$ at time $t$ can only be conditioned on past history of cash-flows. Stated in technical terms, $D$ must be adapted to the filtration generated by the Brownian motion $\left\{w_{t}\right\}_{t \geq 0}$. Third, we assume that $D$ is right-continuous (upward jumps in $D$ represent lumpy dividend payments). Finally, $D$ must satisfy the liquidity constraint, which requires that $s_{t} \geq 0$ for all $t$, where the dynamics of the cash balance $s_{t}$ are given by:

$$
d s_{t}=\left(x_{t}-c+r s_{t}\right) d t-d D_{t}
$$

The firm is forced to exit if $x_{t} \leq c$ and $s_{t}=0$, so the exit time $\tau$ is given by

$$
\tau:=\inf \left\{t \geq 0: x_{t} \leq c \text { and } s_{t}=0\right\}
$$

The objective of the firm is to choose a dividend process to maximize:

$$
\sup _{D} \mathbb{E} \int_{t=0}^{\tau} e^{-\rho t} d D_{t}
$$

subject to (6), (7), and $s_{t} \geq 0$ for all $t \in[0, \tau]$. Note that this formulation allows voluntary exit when $x_{t}<c$ and $s_{t}>0$ by paying out the remaining cash as the liquidation value: $d D_{t}=s_{t} \cdot{ }^{4}$

The firm's problem becomes much more intuitive once recast as a Markovian control problem with suitably chosen state variables. Note that the history at time $t$ consists of past cash flows $\left\{x_{t^{\prime}}\right\}_{0 \leq t^{\prime} \leq t}$, past dividends $\left\{D_{t^{\prime}}\right\}_{0 \leq t^{\prime} \leq t}$, and the initial cash balance $s_{0}$. Since the cash flow process is Markovian, the part of the history that defines the probability distribution for future incomes is summarized in the current cash flow level $x_{t}$. Similarly, the part of the history that defines the firm's capacity to satisfy the liquidity constraint is summarized as the current cash holdings $s_{t}$, as derived from past cash flows and dividend payments through equation (6). Therefore, the pair $\left(x_{t}, s_{t}\right)$ summarizes the history part that is payoff relevant for the future, and is sufficient for deciding the optimal policy at $t$ by the Bellman's Principle of Optimality. Consequently, we may denote by $V(x, s)$ the value of the firm that solves (8) starting from an arbitrary state point $\left(x_{0}, s_{0}\right)=(x, s)$.

\footnotetext{
${ }^{4}$ We allow voluntary exit when $x_{t}>c$, but this would never be optimal.
} 
In effect, the problem of the firm is to choose between three policy options at each point of the state space. First, the firm may exit, which is irreversible, and results in the exit value $s_{t}$. Second, the firm may pay a positive dividend $d D_{t}$ to the owners, which shifts the firm in the state space to cash balance level $s_{t}-d D_{t}$. Third, the firm can continue without paying dividends, in which case the cash balance evolves according to

$$
\frac{d s_{t}}{d t}=x_{t}-c+r s_{t} .
$$

The solution to the firm's problem is a division of the $(x, s)$-space into regions in each of which one of the three policy options is optimal. The following Proposition characterizes the solution in the case where $r<\rho$ (the special case $r=\rho$ will be discussed later). For illustration, see Figure 1.

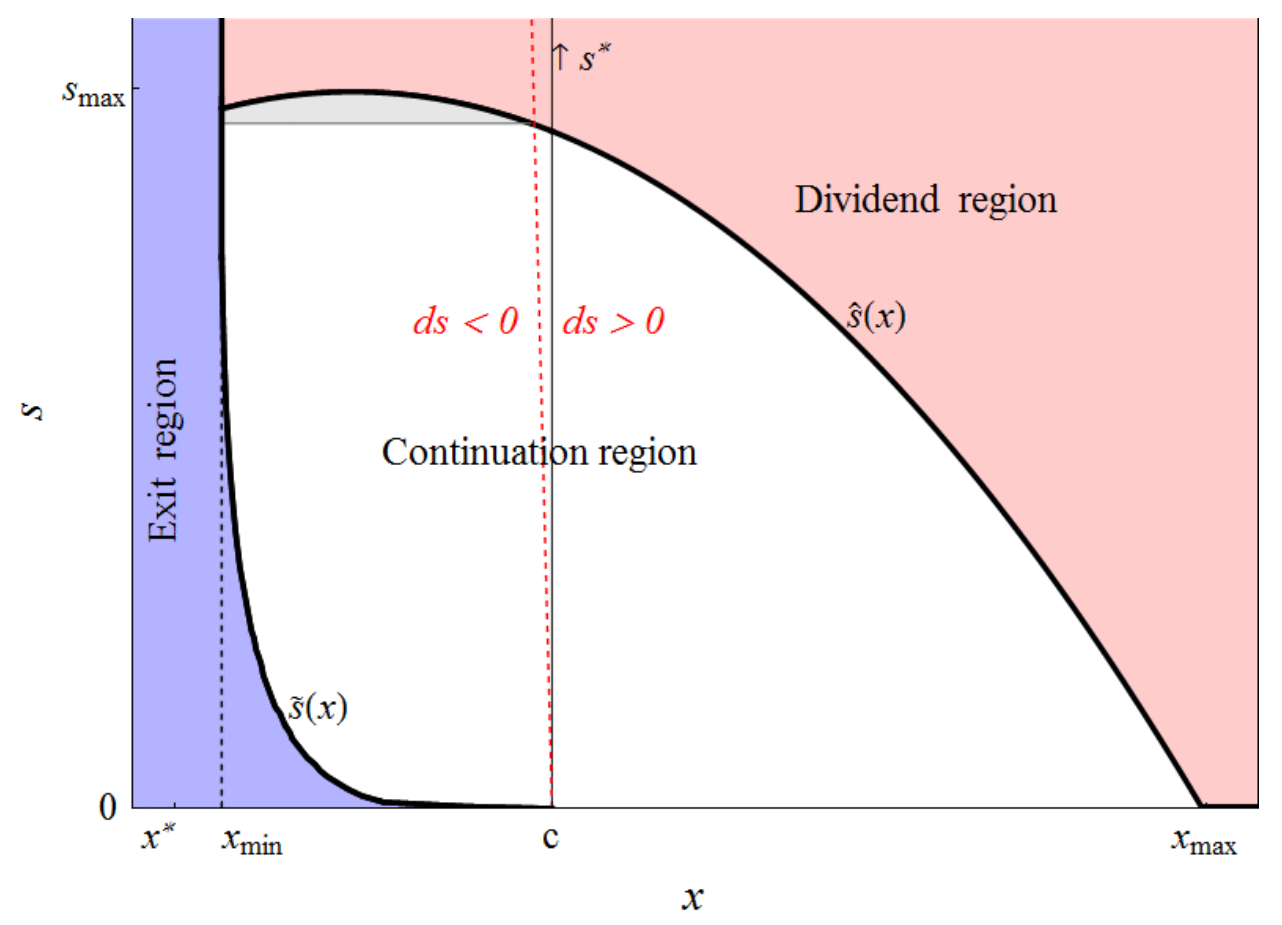

Figure 1: Optimal policy regions of a liquidity constrained firm, with exit boundary $\widetilde{s}$ and dividend boundary $\widehat{s}$ in the state space of revenue $x$ and cash holdings $s$. The steep dashed line ending at the zero profit-zero cash point $(c, 0)$ shows where $d s=0$. The small gray region is a transitory region inside the continuation region. 
Proposition 1 (Optimal policy when $0 \leq r<\rho$ ) There are constants $x_{\min } \in\left(x^{*}, c\right)$, $x_{\max }>c$, and $s_{\max }>0$ such that the optimal policy has the following features:

1. If $x_{t} \leq x_{\min }$, it is optimal to exit immediately irrespective of $s_{t}$.

2. If $x_{\min }<x_{t}<c$, then there is a cut-off value $\widetilde{s}\left(x_{t}\right)>0$ such that it is optimal to exit if and only if $s_{t} \leq \widetilde{s}\left(x_{t}\right) . \widetilde{s}\left(x_{t}\right)$ is decreasing in $x_{t}$ and $\lim _{x_{t} \rightarrow c} \widetilde{s}\left(x_{t}\right)=0$.

3. If $x_{t} \geq c$, it is optimal not to exit, irrespective of $s_{t}$.

4. If $x_{t}>x_{\max }$ or $s_{t}>s_{\max }$, it is strictly optimal to pay out some dividends (and continue thereafter, if $x_{t}>x_{\min }$ ).

The proof is in Appendix A. Figure 1 illustrates the optimal policy. This is the key figure of our paper. The life span of a firm is a stochastic path in the $(x, s)-$ space. While the firm stays inside the continuation region its law of motion is given by equations (1) and (9). The gray area inside the continuation region is a transitory region: after leaving it, a firm that follows the optimal policy cannot return there. The firm never ventures inside the dividend region, because payouts (which move the firm down along $s$-axis) keep it from crossing the boundary of that region. When revenue $x$ is sufficiently high, the dividend region reaches all the way to the $s=0$ line, where the firm operates with zero cash holdings and continually pays out all of the profit flow as dividends. The firm's life span ends when it hits the boundary of the exit region for the first time.

We will next explain the intuition for why the optimal policy takes the form depicted in Figure 1.

\section{Continuation Region}

The point of accumulating cash is to use it as a buffer that prevents inefficient exit. To see this, consider a situation where the firm's current cash holding $s_{t}$ is small but strictly positive, and where the profit flow is exactly zero, i.e. $x_{t}=c$. The firm is not currently making losses and there is a positive option value associated with future profits, so it cannot be optimal to exit. Neither can it be optimal to pay out $s_{t}$ as dividends, because this would cause the firm to immediately move down to the point $(x=c, s=0)$, which means that the firm is forced to exit within the "next instant" thus losing the option value. Therefore, there must be a non-empty 
continuation region, where it is optimal to retain cash inside the firm despite the difference between the discount rate and the rate of return on cash holdings.

Now let's consider the properties of the value function in the continuation region. Define the value of the constrained firm $V(x, s)$ as gross of the cash holdings, so the value at the time of exit is $V(x, s)=s$. Using Ito's lemma, we can write the differential $d V$ as:

$$
d V(x, s)=V_{s}(x, s) d s+V_{x}(x, s) d x+\frac{1}{2} V_{x x}(x, s)(d x)^{2} .
$$

Taking the expectation and letting $d t$ be small yields:

$$
E(d V)=V_{s}(x, s) d s+V_{x}(x, s) \mu x d t+\frac{1}{2} V_{x x}(x, s) \sigma^{2} x^{2} d t
$$

where $d s$ is from (9). The Bellman equation is $V(x, s)=E(V+d V) /(1+\rho d t)$, which can be solved for $\rho V d t=E(d V)$, leading to the following PDE:

$$
\rho V(x, s)=(x-c+r s) V_{s}(x, s)+\mu x V_{x}(x, s)+\frac{\sigma^{2}}{2} x^{2} V_{x x}(x, s) .
$$

Note that this PDE does not contain a cash flow term. The reason is that, in the continuation region, the cash flow between the firm and its owners is zero: Positive cash flow adds to the cash balance and negative flow subtracts from it.

The PDE (11) does not have a closed-form solution. Further, it is valid only in the continuation region, the boundaries of which must be optimally chosen as part of the solution. We will next discuss the properties of these boundaries, which constitute the optimal exit and dividend policies. The numerical solution of the problem is discussed in Section 3.

\section{Exit Policy}

The liquidity constraint can only reduce the continuation value of the firm, so the constrained firm should certainly exit whenever the unconstrained would, i.e., when $x_{t} \leq x^{*}$. In addition, the firm is forced to exit when it has no cash to cover the current loss, i.e., when $\left(x_{t} \leq c, s_{t}=0\right)$. This gives a fixed boundary for the value of the firm:

$$
V(x, 0)=0 \text { for } x \leq c .
$$

The firm should clearly never exit while current profits are positive $\left(x_{t}>c\right)$. Now consider a firm with a very small $s_{t}$ and with $x_{t}<c$. This firm is depleting its cash 
but could in principle still continue. However, it is very likely to be forced to exit in the near future. For any $x_{t}<c$, and for sufficiently small $s_{t}$, the firm is so unlikely to bounce back to a positive cash flow before $s$ hits zero that the owners are better off exiting immediately and just taking the remaining $s_{t}{ }^{5}$ Thus, there must be a boundary between exit and continuation regions that lies strictly above $s=0$ for $x<c$. We call exiting when $x_{t}>x^{*}$ and $s_{t}>0$ precautionary exit.

We denote the exit threshold by $\tilde{s}(x)$, defined in $x \in\left[x_{\min }, c\right]$ where $x_{\min }$ is, in practical terms, the lowest revenue at which the firm ever operates. The lower is $x_{t}$, the less valuable the continuation value of the firm, and thus the higher the $s$ required for continuation to be optimal, so $\tilde{s}^{\prime}(x)<0$ in $x \in\left(x_{\min }, c\right)$.

Inside the continuation region the value of the firm must exceed the exit value $s$. At the exit boundary the firm is indifferent between taking the exit value and the continuation value, so

$$
V(x, \tilde{s}(x))=s .
$$

Inside the continuation region the marginal value of cash must be at least unity, else the owners would be better off by paying out cash. Smooth pasting at the exit boundary requires

$$
\begin{aligned}
& V_{s}(x, \tilde{s}(x))=1, \\
& V_{x}(x, \tilde{s}(x))=0 .
\end{aligned}
$$

It may seem unintuitive that the exit boundary is strictly above zero for all $x<c$. To see this point more formally, suppose, by contrast, that the continuation region in fact reached all the way down to $s=0$ for some interval $\left[x^{\prime}, c\right]$, where $x^{\prime}<c$. Since a cashless firm is forced to exit at $s=0$, the boundary value $V(x, 0)=0$ is fixed for all $x \leq c$. This implies that the first and second derivatives with respect to $x$ must also be zero within this interval: $V_{x}(x, 0)=V_{x x}(x, 0)=0$ for all $x \in\left(x^{\prime}, c\right)$. Substituting these into the PDE (11) that holds in the continuation region yields $V_{s}(x, 0)=0$ within this interval. But this leads to a contradiction, because $V_{s} \geq 1$ must hold in the continuation region, or else cash would be more valuable outside than inside the firm. It follows that the continuation region cannot reach down to $s=0$ for $x<c$.

The only way in which a firm following the optimal policy can extinguish all funds is to hit exactly the zero-flow-zero-stock point for cash, $\left\{x_{t}, s_{t}\right\}=\{c, 0\}$. Thus the

\footnotetext{
${ }^{5}$ It can be shown that the probability with which the firm bounces up to positive profits before running out of cash goes to zero at a rate faster than $s$.
} 
constrained firm will experience a forced exit with probability $0 .{ }^{6}$ Practically all exit by liquidity constrained firms is precautionary.

We assume that the scrap value of the firm is zero, so the exit value of the firm is simply equal to its cash holdings. In the unconstrained case, adding a positive scrap value would be equivalent to adding the rental opportunity cost of the scrap value to the flow cost. However, in the presence of a liquidity constraint an opportunity cost is not equivalent to an operating cost as only the latter requires liquidity. In the extreme, having a scrap value so high that the optimal exit threshold of an unconstrained firm is positive, the firm cannot face negative cash flows during its lifetime so the liquidity constraint is redundant. Apart from this extreme case, the problem would not be qualitatively changed by a positive scrap value.

\section{Dividend Policy}

When $r<\rho$, holding cash is costly. The benefit of holding cash is that it may allow the firm to avoid a forced exit in the future when the option value of continuation would still be positive. This benefit is bounded above by $V^{*}(c)$, the unconstrained continuation value at the zero profit flow. Since the cost of holding cash increases without bound in $s$, there exists, for any $x$, some $s$ high enough such that it is better to stop accumulating cash. This threshold value, denoted $\hat{s}(x)$, defines the boundary between the continuation region and the dividend region. It can be interpreted as a target level of cash holdings that depends on current profitability. The firm makes payouts to owners to make sure it doesn't hold more than the target level of cash; hence we call $\hat{s}$ the dividend threshold. The value of the firm above the dividend threshold must be:

$$
V(x, s)=V(x, \hat{s}(x))+(s-\hat{s}(x)), \text { when } s>\hat{s}(x) .
$$

For sufficiently high $x$ the possibility of forced exit is so remote that it is not worth holding on to any cash. We denote the threshold above which it is optimal to not hold any cash by $x_{\max }$. In the limit $x \rightarrow \infty$, the prospect of forced exit becomes irrelevant, and thus the value of the firm must converge to the value of the unconstrained:

$$
\lim _{x \rightarrow \infty} V(x, s)=V^{*}(x)+s .
$$

\footnotetext{
${ }^{6}$ The firm's position in $(x, s)$-space cannot evolve along the boundaries of the continuation region because, if $s_{t}=0$ and $x_{t}>c$ then $d s>0$, and if $x_{t}<c$ then the firm exits if it hits the boundary $\{x, \tilde{s}(x)\}$.
} 
At the dividend threshold, cash is equally valuable inside as it is outside the firm, where one dollar is of course worth one dollar. Thus, the value matching condition

$$
V_{s}(x, \hat{s}(x))=1
$$

must hold at the dividend threshold. The associated smooth-pasting condition requires $^{7}$

$$
\begin{aligned}
& V_{s s}(x, \hat{s}(x))=0, \\
& V_{x s}(x, \hat{s}(x))=0 .
\end{aligned}
$$

The firm is constrained at the margin only in the continuation region; there having a dollar more would increase the value of the firm by more than a dollar: $V_{s}(x, s)>1$.

When the firm hits the dividend threshold from inside it pays out just enough cash to not cross the boundary. However, if the firm were to start at $s_{0}>\hat{s}\left(x_{0}\right)$, then it would immediately pay out the excess $s_{0}-\hat{s}\left(x_{0}\right)$ as a lump sum dividend. (For a new firm this means that the owners have more than enough funds to endow the firm with the optimal level of precautionary cash holdings; the "lump dividend" at the start is then the cash that owners retain for themselves.) A lump sum dividend is also paid out as the liquidation value upon precautionary exit. Note that if a firm that enters the industry at revenue level $x_{0}$ can choose its initial cash holdings then $s_{0}=\hat{s}\left(x_{0}\right)$ is the optimal choice.

\section{Comparative Statics}

We next illustrate how the firm's optimal policy depends on the parameters of the stochastic process. To do this, we solve the optimal policy numerically in a manner to be explained in Section 3. We vary one parameter at a time from a set of baseline parameters. The results are depicted in Figure 2. The solid lines mark the borders of the continuation region in the liquidity constrained case, and the vertical dashed lines mark the optimal exit threshold in the unconstrained case. The left panel shows the relation of the optimal policy and $\sigma$, the volatility of the cash flow process. As is well known, the unconstrained exit threshold $x^{*}$ is decreasing in $\sigma$. Here the increased option value shows up as an enlarged continuation region. As in the unconstrained

\footnotetext{
${ }^{7}$ In terms of Dumas (1991), the dividend is "an infinitesimal requlator" (while exit is a discrete regulator) so there must be "super-contact" at $\hat{s}(x)$.
} 
case, higher volatility makes it optimal to accept bigger losses because it increases the upside potential while the downside is still protected by the exit option. Furthermore, the dividend boundary shifts out to the right also because, at any given $x$, higher volatility increases the risk of facing forced exit within any given period of time.

The right panel of Figure 2 shows the effect of varying $\mu$, the percentage drift of the cash flow process. Higher $\mu$ increases the option value at any given level of losses, as the firm is more likely to bounce back to positive profits within any given period of time. However, higher $\mu$ also makes the firm safer at any given point - by making it less likely that forced exit would threaten it within any given time - so it is not obvious that a higher $\mu$ should also shift out the dividend boundary. However, we have found no examples of the opposite.
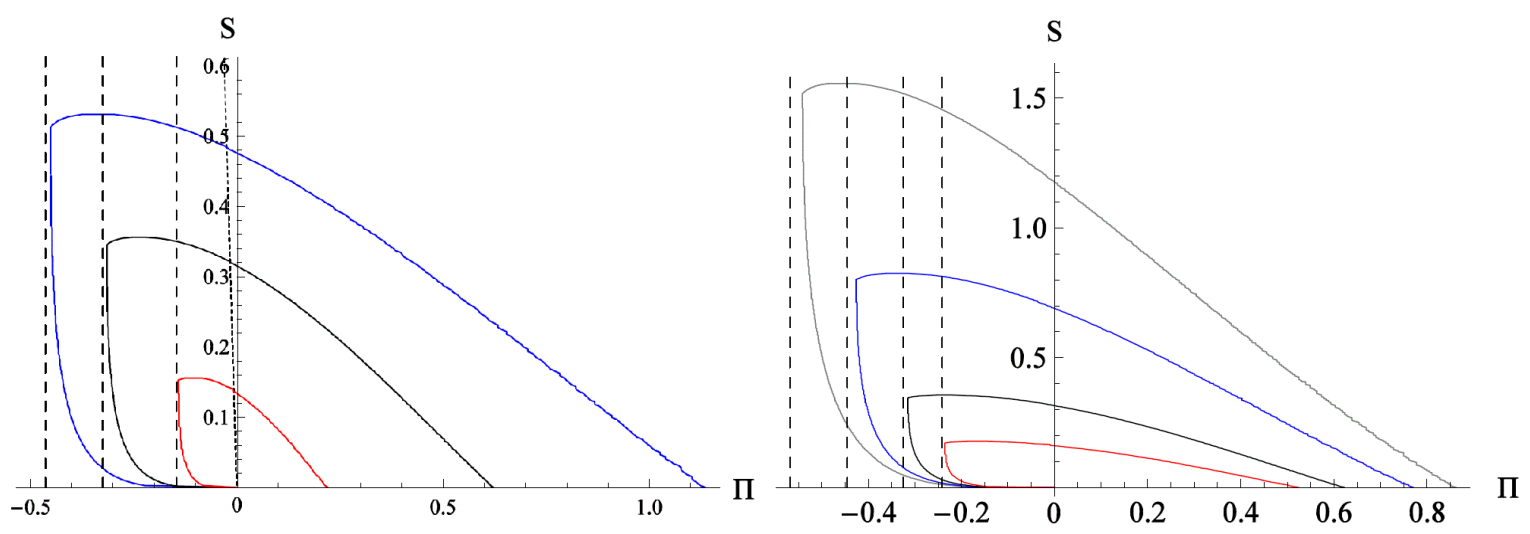

Figure 2: Comparative statics of the optimal policy around baseline parameter values $r=0.05, \rho=0.1, \mu=0, \sigma=0.25, c=1$. Left panel: volatility: $\sigma \in\{0.1,0.25,0.4\}$, from smallest to largest region. Right panel: drift: $\mu \in\{-0.05,0,0.05,0.09\}$, from smallest largest region.

\subsection{Special Case: No Liquidity Premium $(r=\rho)$}

Consider now the special case in which there is no liquidity premium: $r=\rho$. Hoarding cash is now costless, so it can never be strictly optimal to pay dividends. The optimal policy is thus defined by dividing the $(x, s)$ - space between the exit region and the continuation region. The qualitative properties of the exit region and the exit threshold $\tilde{s}(x)$ are the same as with $r<\rho$. 
Holding cash inside the firm can be strictly optimal only when there is a positive probability of being forced to exit in the future. Of course, no matter how high $x_{t}$, falling below $x^{*}$ always remains possible. However, the worst-case cash flow under which the owners would ever want to continue is the cash flow at the unconstrained exit policy, $x^{*}-c$. The firm becomes irreversibly unconstrained if it accumulates so much cash that the interest income from its cash holdings could be used to cover the worst-case losses forever. This defines the escape level of cash as

$$
s^{*}=\frac{c-x^{*}}{r} .
$$

This means that a fixed boundary condition

$$
V\left(x, s^{*}\right)=V^{*}(x)+s^{*}
$$

now replaces the free boundary $\hat{s}(x)$ seen in the $r<\rho$ case. For $s_{t} \geq s^{*}$, the firm is indifferent between paying dividends or not and $V(x, s)=V^{*}(x)+s$. Above the escape level of cash, the firm can no longer run out of cash before first becoming so unprofitable that it would want to exit even in the absence of a liquidity constraint. As the firm is then in effect unconstrained, its exit policy is the same as that of an unconstrained firm: exit if and only if $x \leq x^{*}$. We summarize these results in the following proposition:

Proposition 2 (Optimal policy when $0 \leq r=\rho$ ) If $x_{t}>x^{*}$ and $s_{t}<\left(c-x^{*}\right) / r$, it is strictly optimal to refrain from paying dividends. If $x_{t}>x^{*}$ and $s_{t}>\left(c-x^{*}\right) / r$, the owners are indifferent between paying dividends and continuing without paying dividends. The optimal exit policy is qualitatively the same as when $r<\rho$ (see Proposition 1).

The special case without a liquidity premium is quite similar to the setup of a financially constrained firm in Mello and Parsons (2000). They study optimal hedging, namely how firms should use futures contracts on an asset that is correlated with their profits to reduce the risk of inefficient exit. They do not take into account that the firm becomes permanently safe from inefficient exit at a finite level of cash holdings, but instead assume that the constrained firm's value reaches that of the unconstrained case only in the limit of infinite cash holdings. The environment faced by the agent in DeMarzo and Sannikov (2008) also features serially correlated cash 
flow and saving is possible without liquidity costs; there precautionary exit does not arise because expected cash flow is assumed to be always positive (due to a parameter restriction which implies that the exit threshold is always positive). There is also no liquidity premium in the model of Gryglewicz (2011), so it is never strictly optimal to pay out dividends. To generate predictions about the dividend policy he assumes that the firm pays dividends at the indifference boundary, which is equivalent to our $s^{*}$ (but is changing over time due to learning).

\section{Small Liquidity Cost}

It turns out that the optimal policy, in particular the dividend policy, is very sensitive to small liquidity costs. Figure 3 shows the impact of varying the return on firm's cash holdings, $r$. As $r$ gets closer to $\rho$ it becomes less costly to hold cash so continuation is everywhere more attractive and the continuation region expands. The limiting case results in the escape level of cash $s^{*}$, from (20), that is much higher than the highest cash holdings that the firm would ever keep even at a liquidity premium of just one basis point. The limiting case is qualitatively different, because there is no trade-off between the liquidity cost of the cash holdings and the expected benefit of preventing exit. ${ }^{8}$ However, while the optimal payout policy is very sensitive to $r$ near $\rho$, the value of the firm is not. When $r$ is very close to $\rho$ the liquidity cost is negligible, and there is a large region in state space where the firm is almost indifferent between retaining and paying out cash. (There the marginal value of cash, $V_{s}$, is only very slightly above unity). The high sensitivity of optimal policy to $r$ near $\rho$ means that, even if the liquidity premium were close to zero, the optimal behavior of firms would not be well approximated with a model where the liquidity cost is completely assumed away.

\subsection{Generalization: New Cash Injections}

The assumption that the firm can not raise new cash is quite stark, and is made in order to identify the effects of the liquidity constraint in its most transparent form. Here we generalize the model to the case where owners can increase the firm's cash

\footnotetext{
${ }^{8}$ It can be shown that as the optimal policy converges to the limiting case as $r \uparrow \rho$, in the sense that, for every point $\left(x^{\prime}, s^{\prime}<s^{*}\right)$ in the continuation region of the limiting case $r=\rho$, there exists $r^{\prime}<\rho$ for which $\left(x^{\prime}, s^{\prime}\right)$ is in the continuation region.
} 


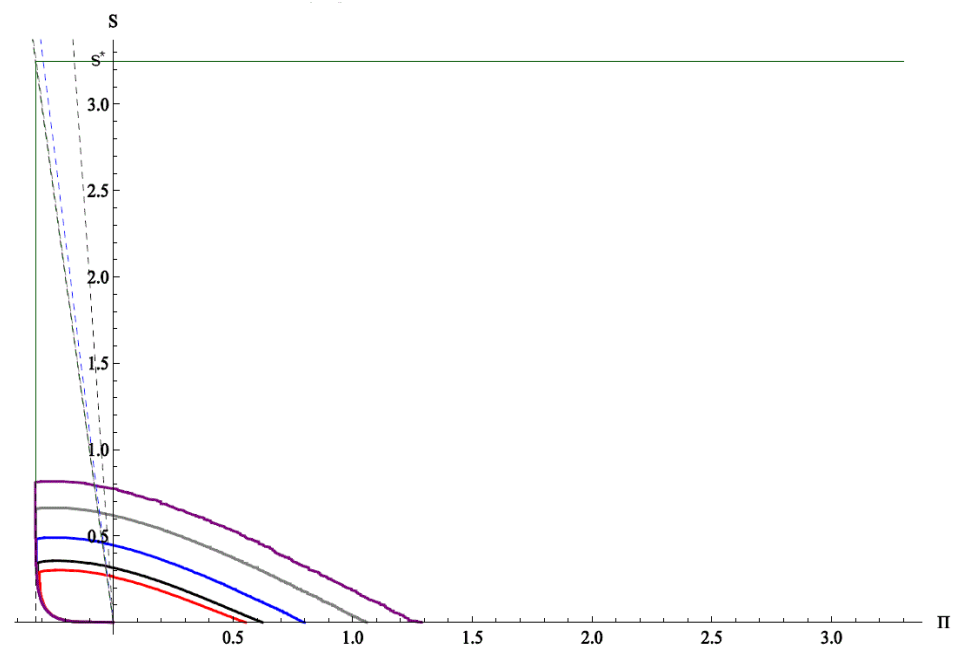

Figure 3: Optimal policy at varying levels of the liquidity premium $\rho-r$. Discount rate is held fixed at $\rho=0.1$; other parameters are held at $\mu=0, \sigma=0.25, c=1$, and $r \in\{0,0.05,0.09,0.099,0.1\}$ from smallest to largest regions. In the limiting case $r=\rho$ there is no actual dividend region, but above the escape level of cash $s^{*}$ the owners are indifferent between hoarding and paying out cash.

holdings at some transaction cost. Specifically, suppose that they can, at any point in time, inject any amount $s$ of cash at $\operatorname{cost} \xi+(\gamma+1) s$, where $\xi$ is the fixed and $\gamma$ the marginal transaction cost. The injection of cash causes the firm to jump directly upwards in the state space $(x, s)$.

Paying the transaction cost can only be optimal when the firm would otherwise face immediate forced exit $(s=0$ and $x<0)$ because otherwise the cost could still be postponed and, with luck, even avoided. If the firm decides to incur the transaction cost, then its target level of cash is

$$
s^{+}(x)=\arg \max _{s}\{V(x, s)-(1+\gamma) s\} .
$$

The target level $s^{+}$equalizes the marginal cost of new cash and its marginal value at the firm, $V_{s}\left(x, s^{+}(x)\right)=1+\gamma$. Transaction costs are independent of current revenue $x$, so raising cash must be more desirable the higher the current $x$ (as long as $x<0$ ). Therefore, if raising cash is ever optimal, then there must be some $x_{\min }^{+} \in\left(x^{*}, 0\right)$ such that cash is raised on an interval $\left\{s=0, x \in\left[x_{\min }^{+}, 0\right]\right\}$ and nowhere else. The lowest $x$ where the firm replenishes its cash holdings, $x_{\min }^{+}$, is the point where the value of 
exit (which is zero on the $s=0$ line) is just equal to the value of continuing from $\left\{x, s^{+}(x)\right\}$ net of the transaction cost of moving there:

$$
V\left(x_{\min }^{+}, 0\right)=V\left(x_{\min }^{+}, s^{+}\left(x_{\min }^{+}\right)\right)-\xi-(1+\gamma) s^{+}=0 .
$$

If transaction costs are sufficiently high then it is never optimal for the firm to raise new cash. This is the case when $\max _{s}\{V(0, s)-(1+\gamma) s-\xi\} \leq 0$, i.e., the firm's value net the transaction cost would be negative. Notice that "prohibitive" transaction costs are finite, because the benefit (from some probability of inefficient exit prevented) is necessarily finite.

We describe in Section 3 how the optimal policy with new cash injections can be solved numerically. Figure 4 depicts the optimal policy for a firm that faces positive but not prohibitive transaction costs. The qualitative difference to the optimal policy in the basic model (recall Figure 1) is the segment of horizontal axis where cash is raised and the associated target curve $s^{+}(x)$ directly above. For sufficiently low cash flow the firm still finds it optimal to exit with positive cash holdings rather than incur the transaction cost.

Holding cash is costly when $r<\rho$, so without a fixed transaction cost firms would raise cash continuously only to offset a contemporaneous negative cash flow. The fixed cost makes it is optimal to raise new cash in lumps in order to postpone the prospects of having to incur it again. In the absence of a marginal transaction cost it would be optimal to "jump" all the way to the dividend boundary. Any transaction costs reduce the value of continuation and shift the exit boundary to the right.

The unconstrained case, with the simple exit threshold $x^{*}$ in (3), is the limiting case where both the fixed and the marginal transaction cost are zero. The constrained case, where the firm never raises new cash, is equivalent to assuming that the cost parameters are prohibitively high. Hence this setup encompasses both the constrained and unconstrained cases of the basic model.

The setup with cash injections allows various interpretations. One literal interpretation is that of a risk-neutral owner-entrepreneur who allocates her wealth between two assets; one liquid asset that can be used to pay off possible losses, and another illiquid asset that yields a higher rate of return but can only be turned into liquid form at a transaction cost. The entrepreneur has deep pockets in terms of the illiquid asset, but the transaction cost makes it desirable to hold some liquid assets as well and, in some circumstances, let the firm fold rather than incur another transaction 


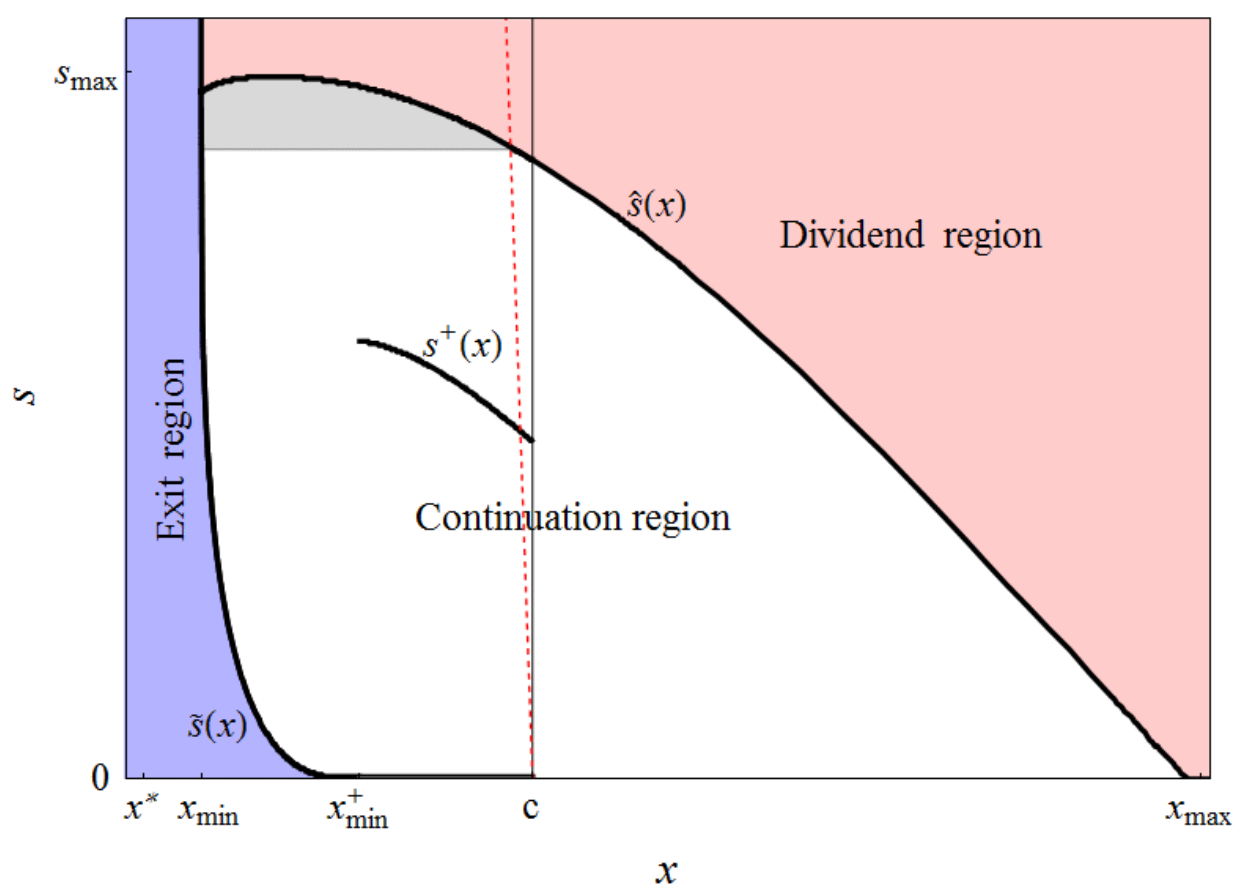

Figure 4: Optimal policy when cash can be raised at a transaction cost. Amount $s^{+}(x)$ of new cash is raised when $s=0$ and $x \in\left[x_{\min }^{+}, c\right]$.

cost.

A broad interpretation of the extended model analyzed in this section is a firm that can raise new equity at a transaction cost. This interpretation is similar to Décamps et al (2011) who analyze the case of non-persistent cash flow risk. Assuming that there is a fixed cost associated with raising equity, the firm delays the recapitalization until it has used up its liquid assets. Then, upon hitting $\left\{s=0, x \in\left[x_{\min }^{+}, 0\right]\right\}$, it will raise new equity in order to increase its cash balance to level $s^{+}(x)$ that equalizes the marginal value of internal cash with the marginal cost of raising equity. The new owners supply the firm with cash and are compensated with an equally valuable stake in the firm. Our calibrated example of industry equilibrium in Section 4.2 will adhere to this interpretation of the firm's problem.

\section{Comparative Statics}

In Figure 5, we illustrate how the level of transaction costs affects the optimal policy. In addition to the case with prohibitive transaction parameters (seen already in Figure 
1), we solve the policy for a case of low and high transaction costs. In each case the exit boundary is further left than under prohibitive costs, as the threat of forced exit is not as grave with the possibility to raise new capital. The lower the transaction costs, the further the exit boundary shifts towards the unconstrained exit threshold. With low transaction costs it is cheap to add cash whenever necessary, so it is possible to reduce the liquidity cost and never hold very much cash, so the continuation region becomes smaller. In the limiting case the firm holds no cash; it pays out profits as they come in, and raises cash as it makes losses.
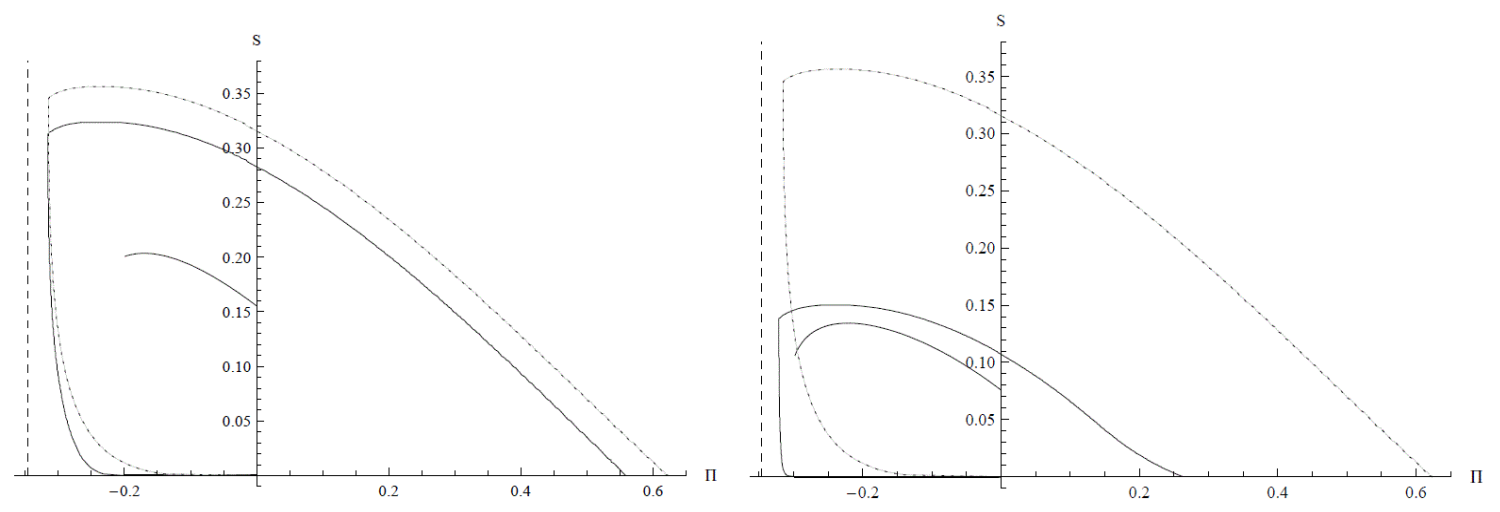

Figure 5: Optimal policy is under high (left panel) and low (right panel) transaction cost parameters: $\gamma=\xi=0.1$ in the case of "low" and $\gamma=\xi=0.005$ in the case of "high" costs. The case with prohibitively high transaction costs (.e., the fully constrained firm) is depicted in dashed curves for comparison. Other parameters are as in Figure 2.

\section{Solution Method}

The PDE defined by (11) and the various free boundary conditions cannot be solved analytically. To solve the firm's problem we turn to a discrete-time approximation of the problem and solve it numerically. ${ }^{9}$ In the binomial process approximation of

\footnotetext{
${ }^{9}$ The program for solving the optimal policy is available at http://www.hse-econ.fi/murto.
} 
geometric Brownian motion the evolution of $x$ is governed by

$$
x(t+\Delta)= \begin{cases}x(t) e^{\sigma \sqrt{\Delta}} & \text { with probability } q=\frac{1}{2}\left(1+\frac{\mu-\frac{\sigma^{2}}{2}}{\sigma} \sqrt{\Delta}\right) \\ x(t) e^{-\sigma \sqrt{\Delta}} & \text { with probability } 1-q\end{cases}
$$

where $\Delta$, the length of the time period, can be set arbitrarily small. ${ }^{10}$ The evolution of the cash balance is now

$$
s(t+\Delta)=(s(t)-\delta(t))(1+r \Delta)+(x(t)-c) \Delta,
$$

where $\delta(t) \in[0, \stackrel{s}{s}(t)]$ is the dividend paid at time $t$. The dividend cannot be so high as to make the cash holdings negative at any point in time, so the maximum feasible dividend is restricted by $\min \{s(t+\Delta), s(t)\} \geq 0$, where $\stackrel{\circ}{s}(t) \equiv s(t)+$ $\min \{0,(x(t)-c) \Delta /(1+r \Delta)\}$.

The value function of the firm, stated in recursive form, is

$$
\begin{aligned}
& V(x(t), s(t) \mid t)= \\
& \max \left\{\begin{array}{c}
s(t), \\
\max _{\delta \in[0, s]}\left\{\delta+\frac{1}{1+\rho \Delta} E[V(x(t+\Delta), s(t+\Delta) \mid t+\Delta)]\right\},
\end{array}\right.
\end{aligned}
$$

where $s(t+\Delta)$ is from (25).

The recursion in (26) satisfies Blackwell's sufficient conditions so it is a contraction mapping. Thus it can be solved by iterating backwards in time: Starting from an arbitrary $V_{T}(x, s \mid T)$ the value function converges to a unique solution that approximates $V(x, s) \cdot{ }^{11}$

Augmenting the value function with the additional option of raising more cash is straightforward. When solving for the optimal policy, (26) is replaced with

$$
\max \left\{\begin{array}{c}
V(x(t), s(t) \mid t)= \\
\max _{\delta \in[0, s]}\left\{\delta+\frac{1}{1+\rho \Delta}[E V(x(t+\Delta), s(t+\Delta) \mid t+\Delta)]\right\}, \\
\max _{s^{+} \in[s(t), \infty)}\left\{V\left(x(t), s^{+} \mid t\right)-\xi-(1+\gamma)\left(s^{+}-s(t)\right)\right\}
\end{array}\right\}
$$

where $s(t+\Delta)$ is from (25). The numerical solution method is otherwise unchanged.

\footnotetext{
${ }^{10}$ This way of discretizing geometric Brownian motion was inspired by Cox, Ross and Rubinstein (1979).

${ }^{11}$ A natural starting point for the backward induction is $V(x, s \mid T)=s$. This means that the problem is turned into a finite-horizon problem with forced exit in the last period. By increasing $T$ the value function at $t=0$ converges to that of the infinite horizon problem.
} 


\section{Industry Equilibrium}

We saw in Section 2 how a liquidity constraint causes firms to exit at higher levels of current revenue compared to unconstrained firms. It might therefore seem obvious that, at the level of an entire industry, the liquidity constraint would cause there to be fewer but on average more productive firms. However, as we next show, this firm-level reasoning is misleading, because it does not take into account the impact that the liquidity constraint has on output price in competitive equilibrium.

In order to analyze the impact of the liquidity constraint on a competitive industry, we use the definition of industry equilibrium similar to Hopenhayn (1992) and Dixit and Pindyck $(1994, \mathrm{Ch} 8.4) .{ }^{12}$ There is a continuum of firms. We assume that for each firm the revenue $x$ depends on firm-specific output or "productivity" $z$ and an endogenous industry-specific output price $p$, so that

$$
x_{t}=p z_{t}
$$

We assume that productivity $z$ follows geometric Brownian motion

$$
d z_{t}=\mu z_{t} d t+\sigma z_{t} d w_{t}
$$

with the shocks $d w_{t}$ independent across firms. New firms of known productivity $z_{0}$ can be established by paying an entry cost $\phi$. Entering firms choose the initial level of cash holdings to maximize value, so that $s_{0}=s^{+}\left(x_{0}\right)$, where $s^{+}$is from (22). (In the fully constrained case $s_{0}$ would have to be an exogenous parameter.) To guarantee the existence of steady state, we assume an exogenous "death rate" $\lambda>\mu$ at which firms are forced to exit with their cash holdings as the exit value (see Appendix B for details). ${ }^{13}$ In steady state, both the dying and the endogenously exiting firms must be balanced by an equal inflow of new firms of type $\left\{z_{0}, s_{0}\right\}$.

The industry faces a demand curve $D(p)$ for its output. We assume that the demand curve is everywhere strictly downward sloping. The equilibrating variables

\footnotetext{
${ }^{12}$ Liquidity constraints are introduced to a similar steady-state setting by Gomes (2001) to study the relation of cash flow and investment, and by Cooley and Quadrini (2001) to study the ageconditional relation of growth and firm size. Jones (2003) averages over simulated time series of individual firms to study the impact of liquidity constraints on the propagation of aggregate shocks.

${ }^{13}$ The risk of exogenous exit changes the firm's optimal policy slightly compared to Section 2: the firms discount the future at rate $\lambda+\rho$ instead of $\rho$ and the Bellman equation of the constrained firm includes a term $\lambda s$ on the right hand side of (11).
} 
are price of output $p$ and mass of firms $m$. Firms are atomistic, so there is no aggregate uncertainty in steady state. As $p$ is constant, the revenue of individual firms (28) follows the same process (1) that we assumed earlier in Section 2. All firms follow the same optimal policy, which in turn results in a stationary distribution of $z$. In steady state, $m$ and $p$ must satisfy market clearing

$$
D(p)=m \bar{z}(p)
$$

where $\bar{z}$ denotes the cross-sectional average output of firms in steady state $(\bar{z}$ depends on $p$ because the exit policy in terms of $z$ depends on $p$ ). Entry is endogenous, so equilibrium must also satisfy the zero-profit condition for entering firms

$$
V\left(p z_{0}, s^{+}\left(p z_{0}\right)\right)=\xi+(1+\gamma)\left(\phi+s^{+}\left(p z_{0}\right)\right)
$$

where the total entry cost includes financing costs for both the "physical" entry cost $\phi$ and the initial level of cash holdings $s^{+} .{ }^{14}$

Equilibrium price is fully determined by the entry condition (31): $p$ must adjust to eliminate expected rents to entrants. (If entry were profitable then more firms would enter and $m$ would increase, and if entry resulted in expected loss then no one would enter and $m$ would decrease.) Since the value function $V$ is increasing in revenue, $p$ is uniquely determined by (31) and $V$ is obtained numerically as described in the previous section. In the unconstrained case the entry condition (31) is replaced by $V^{*}\left(p z_{0}\right)=\phi$, where $V^{*}$ has the closed form seen in $(5)$.

For any $p$, the mass of firms is determined from (30) as $m=D(p) / \bar{z}(p)$. The role of $m$ is merely to close the model. We are not interested in the number of firms but rather on the cross-sectional distribution of productivity, which is independent of $m$ and of the shape of the demand curve because the model has, at industry-level, constant returns to scale. ${ }^{15}$ Thus $m$ and $D$ will not feature in our analysis. ${ }^{16}$

\subsection{Survival of the Fattest}

The model assumes perfect competition, so the only component of welfare that can be affected by the liquidity constraint is consumer surplus, which varies in the opposite

\footnotetext{
${ }^{14}$ Note that entry, unlike recapitalization, may take place at a positive level of revenue.

${ }^{15}$ A doubling of entry flow doubles the steady state industry output.

${ }^{16}$ For a more detailed exposition of this industry equilibrium concept, see Miao (2005), who studies capital structure (in the absence of liquidity constraints).
} 
direction as $p$. Maximum welfare is, of course, attained in the unconstrained case, so the liquidity constraint can only increase $p$. In real terms, there are potentially three different components to the price distortion: higher aggregate entry cost (due to higher turnover), lower average productivity, and higher liquidity costs. As it turns out, turnover and productivity can move to either direction.

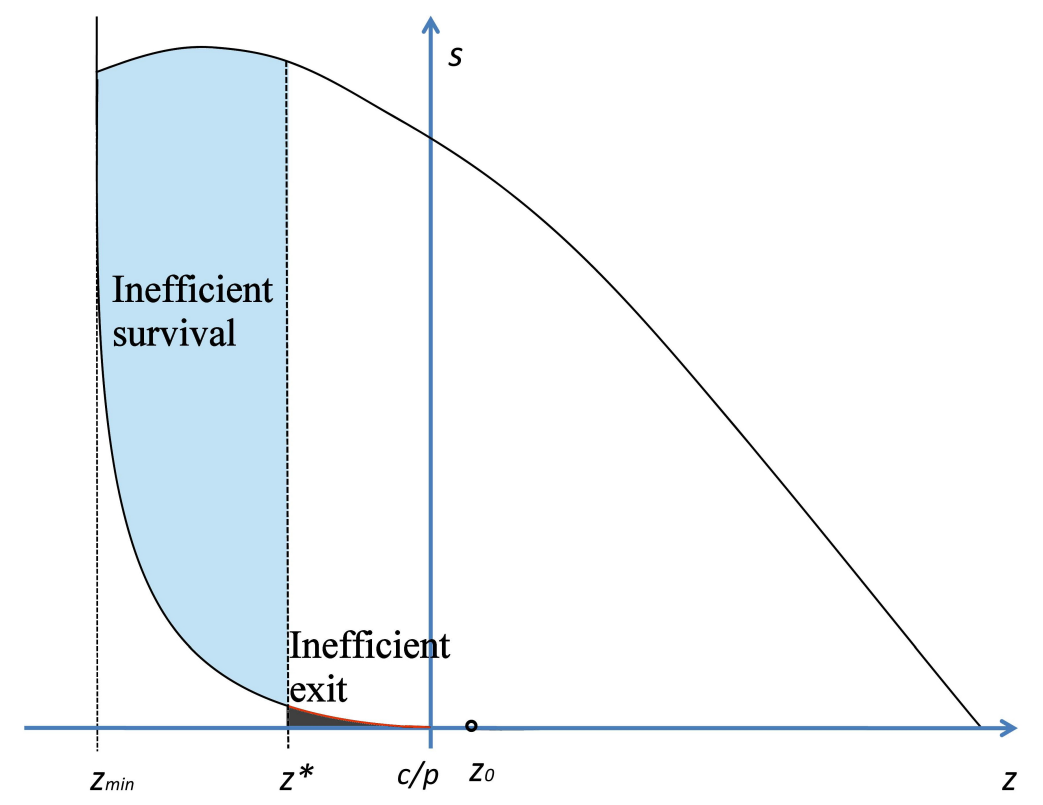

Figure 6: Liquidity constraint and average productivity in industry equilibrium.

To understand why the impact of the liquidity constraint on mean productivity is ambiguous, consider, for simplicity, the fully constrained case where there are no cash injections. Suppose that the entering firms have no cash holdings $\left(s_{0}=0\right)$. The position of firms in $(z, s)$-space is illustrated in Figure 6. Entry level $z_{0}$ is at the point to the right of the zero-profit level $(z=c / p)$ where the continuation value matches the entry cost. As price is distorted upwards, the lowest type to ever continue $\left(z_{\min }\right)$ is below the unconstrained exit threshold $\left(z^{*}\right)$, even though the associated revenue level is higher (Recall $x_{\min }>x^{*}$ in Figure 1). The higher price makes it optimal for firms with sufficient cash reserves to continue at productivity levels that would trigger exit in the unconstrained world. The light shaded region (inefficient survival) covers firms that would exit in the unconstrained solution but stay in under the liquidity constraint. The dark region (inefficient exit) covers firms that are more productive 
than the unconstrained exit threshold $z^{*}$ but exit due to the liquidity constraint. Whether mean productivity is increased or decreased by a liquidity constraint depends on which of these two effects dominates. ${ }^{17}$ In the working paper version of this paper we analyze numerically how the steady state outcomes vary in $z_{0}$ and $s_{0}$ and show that mean productivity is decreased when the entry cost is sufficiently low (see Murto and Terviö, 2010). Here we instead move to a calibrated example with cash injections.

\subsection{A Calibrated Example}

We now present a quantitative example based on the general model with cash injections, using the transaction cost parameters estimated by Hennessy and Whited (2007) with U.S. data. They estimated that (financial companies excluded) the marginal cost of raising new equity is $\gamma=0.09$ and the fixed cost of recapitalization is $\xi=\$ 59,800 .{ }^{18}$ We take most parameters from Miao (2010), who also models the firm revenue process as a geometric Brownian motion. Specifically, we set the drift $\mu=0.0075$, volatility $\sigma=0.15$, the exogenous firm death rate $\lambda=0.04$, and the discount rate $\rho=0.0525$. We set the liquidity premium at $\rho-r=0.01$, the same as used by Décamps et al (2011), which results in $r=0.0425$.

We are left with the fixed operating cost $c$ and entry $\operatorname{cost} \phi$. We aim to choose these parameters so as to match a firm turnover rate of 0.07 and the recapitalization rate of 0.175. We take the turnover rate from Miao (2010) and the recapitalization rate is estimated by Hennessy and Whited (2007). We aim to choose the fixed operating cost $c$ and entry cost $\phi$ in order to match the firm turnover and recapitalization rates with the targets. To do this, we calculate the steady state firm distributions for a wide range of combinations $c$ and $\phi$. This is done by first solving numerically the optimal firm policy (as explained in Section 3). The steady state distribution is then obtained by iterating the firm distribution according to this policy until the distribution converges (see Appendix B for more details). Various statistics including turnover rate and recapitalization rate are then readily computed from the steady state distribution.

\footnotetext{
${ }^{17}$ If $s_{0}$ is sufficiently high and $\phi$ not too high then $z_{0} \in\left(z^{*}, c / p\right)$ and the picture is more complicated, as some of inefficiently exiting firms are replaced by less productive firms.

${ }^{18}$ Hennessy and Whited estimate the costs separately for small and large firms, as well as for the total population of non-financial firms. In our model, small firms can become large and vice versa, so we use their results for the total population.
} 
Figure 7 depicts the contours of our calibration targets in the space of endogenously determined parameters (entry cost $\phi$, operation cost $c$ ). Holding fixed $c$, equilibrium turnover (lighter contours) is decreasing in $\phi$; this is natural as $\phi$ is from the economy's point of view a cost of replacing underperforming firms with new ones. Less obviously, the recapitalization rate (black contours) is also decreasing in $\phi$, even though a higher entry cost makes recapitalization more attractive relative to "replacing" the entire firm. However, higher entry cost also implies a higher equilibrium price of output, so entering firms (whose productivity is exogenous) are more profitable and thus less likely to need a recapitalization.

The shapes of the target curves make it clear that there is a unique match $\left(\phi^{*}, c^{*}\right)$. To understand why this is so, consider for a moment scaling up all cost parameters $(\phi$ and $c$, as well as transaction costs $\gamma$ and $\xi$ ). Such a change would amount to scaling of monetary units, so equilibrium price would also be scaled by the same factor. In $(\phi, c)$ space space such scaling amounts to moving along a ray from the origin, so turnover rate would be constant along any ray. However, in the calibration, transaction cost parameters are fixed, so while moving out on a ray from the origin recapitalization becomes relatively cheaper. This explains why contours of recapitalization rate bend downwards so that the recapitalization rate is higher further out from the origin on any ray. Recapitalizing an existing firm and replacing it with a new firm (turnover) are substitutes from welfare point of view. Turnover contours bend in upwards so the turnover rate is decreasing along a fixed ray from the origin. As seen in the figure, this implies exactly one point where both targets are matched at the same time.

The unique match of the calibration targets is at $\phi^{*}=0.48, c^{*}=0.12$. This implies a fixed one-time entry cost of $\$ 480.000$, and a yearly fixed cost of $\$ 120,000$. In interpreting these figures, note that we do not explicitly model inputs such as labor and physical capital. The revenue is best interpreted as describing revenue net of adjustable inputs under a constant returns to scale production technology.

Having calibrated the model, we calculate other steady state outcomes at the calibrated parameter values. To quantify the impact of financial frictions, we also calculate the corresponding distributions in the absence of transactions costs (see Appendix B for details). The top row of Table 1 reports the key figures. Equilibrium output price is $7.2 \%$ higher than in the absence of transaction costs. Resulting average productivity is $3.6 \%$ higher than in the absence of transaction costs. Thus, at the calibrated parameters, the productivity-enhancing effect of excessive "weeding out" 


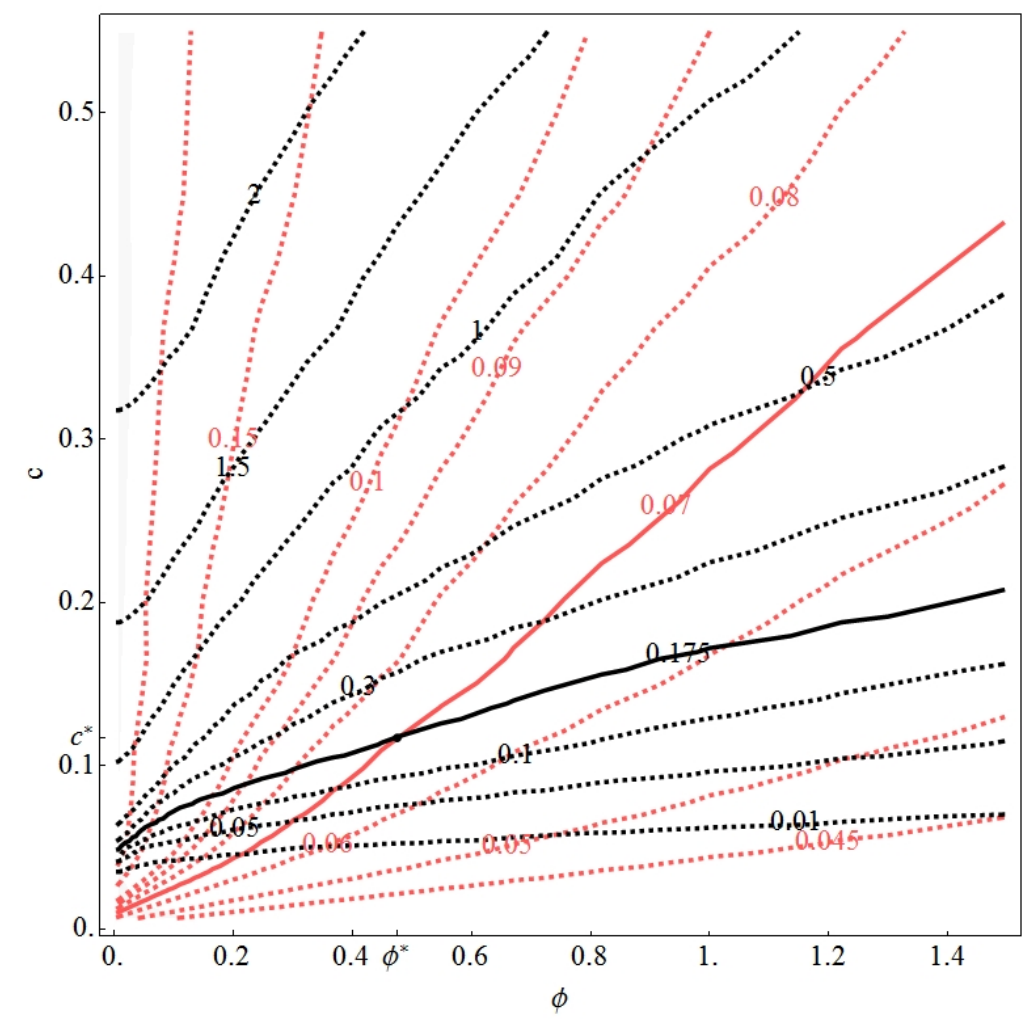

Figure 7: Level curves of calibration targets in the space of endogenously determined parameters. Dashed black curves the recapitalization rate, and the lighter dashed curves depict the turnover rate. Target levels are depicted as solid curves.

is stronger than the "survival of the fattest". ${ }^{19}$ As the model has perfect competition, the increase in output price paid by the consumers represents the welfare loss from financial frictions.

Finally, we look at the robustness of the industry outcomes with respect to our key parameters. First, we replace the transaction cost parameters taken from Hennessy and Whited (2007) with the corresponding parameter values taken from Gomes (2001), namely $\gamma=0.028$ and $\xi=\$ 80,000$. Note that Gomes estimates the fixed transaction cost to be considerably higher and the marginal cost lower than Hennessy and Whited (2007). The results are reported in the second row of Table 1 . We see that theses parameters imply somewhat higher entry and operating costs, while the

\footnotetext{
${ }^{19}$ We find that this is reversed if entry cost is set sufficiently low, but this implies turnover rates that are too high to be consistent with this data.
} 
price impact is lower, $4.8 \%$. Second, we investigate how changing the liquidity premium $\rho-r$ affects the results by repeating the calibration exercise with $r=0.475$ (low liquidity premium) and $r=0$ (high liquidity premium). The results are reported in last two rows of Table 1. Both the entry and operating costs are increased (decreased) from baseline case as the liquidity premium is decreased (increased). Making financial frictions more severe by increasing the liquidity premium increases the market price as expected.

\begin{tabular}{lcccc} 
Case & $\phi$ & $c$ & $\Delta p(\%)$ & $\Delta \bar{z}(\%)$ \\
\hline Baseline & 0.49 & 0.12 & 7.2 & 3.6 \\
Gomes (2001) parameters & 0.74 & 0.18 & 4.8 & 3.8 \\
Low liquidity premium & 0.55 & 0.14 & 6.6 & 3.4 \\
High liquidity premium & 0.40 & 0.09 & 8.9 & 4.7
\end{tabular}

Table 1. Calibration results. Matched entry cost $\phi$, fixed operating cost $c$, and the implied percentage impact on steady state price $p$ and average productivity $\bar{z}$.

\section{Conclusion}

We have analyzed the problem of a liquidity constrained firm that faces persistent cash flow uncertainty. We view our model as a natural framework for analyzing how profitability and liquidity jointly affect the firm's exit and payout policies, and how liquidity constraint distorts production at the industry level. We abstract away from some important aspects of firm dynamics such as growth options, agency issues, and choice of financing structure. We are hopeful that our model framework proves useful for future work along these lines.

\section{Appendix A: Proof of Proposition 1}

Preliminaries. We begin by three lemmas that collect together the key properties of $V(x, s)$ utilized in the proof. The first one merely records properties of $V(x, s)$ that are discussed in more detail in Section 2.2 of the main text:

Lemma $1 V(x, s)$ is continuous and increasing in both arguments, and $V(x, s) \geq s$ for all $(x, s)$. Depending on the optimal policy at $(x, s)$ : 
- If it is optimal to exit, then $V(x, s)=s$.

- If it is optimal to continue without paying dividends, then $V(x, s)>s, V_{s}(x, s)>$ 1 , and the following partial differential equation holds locally at $(x, s)$ :

$$
\rho V(x, s)=(x-c+r s) V_{s}(x, s)+\mu x V_{x}(x, s)+\frac{\sigma^{2}}{2} x^{2} V_{x x}(x, s) .
$$

- If it is optimal to pay dividends and continue thereafter, then $V(x, s)>s$ and $V_{s}(x, s)=1$.

Proof. Choosing dividend $d D_{t}=s_{t}$ and exiting immediately thereafter is a feasible policy at every point in state space and gives value $s_{t}$. It follows immediately that $V(x, s) \geq s$ for all $(x, s)$. In particular $V(x, s)=s$ whenever it is optimal to exit and $V(x, s)>s$ whenever it is strictly optimal to continue. The application of Bellman's principle and Ito's lemma imply that if it is optimal to continue without paying dividends, then the value function must satisfy the Hamilton-Jacobi-Bellman equation (32) locally at $(x, s)$, and $V_{s}(x, s)>1$ (see Section 2.2 in the main text). Finally, if it is optimal to pay a positive dividend $d D>0$ and continue thereafter, the principle of dynamic programming gives $V(x, s)=d D+V(x, s-d D)$, which implies that $V_{s}\left(x, s^{\prime}\right)=1$ for all $s^{\prime} \in[s-d D, s]$. Continuity and monotonicity of $V(x, s)$ follow from the properties of state transition dynamics and monotonicity of cash flow with respect to $x$.

Lemma 2 establishes lower and upper bounds for $V(x, s)$ :

Lemma 2 For all $(x, s)$, we have

$$
\underline{V}(x)+s \leq V(x, s) \leq V^{*}(x)+s,
$$

where

$$
\underline{V}(x)=\left\{\begin{array}{c}
\left(\frac{c}{\rho}-\frac{c}{\rho-\mu}\right)\left(\frac{x}{c}\right)^{\beta}+\frac{x}{\rho-\mu}-\frac{c}{\rho} \text { for } x>c \\
0 \text { for } x \leq c
\end{array},\right.
$$

and where $V^{*}(x)$ is given by (5) and $\beta$ is given by (4) in the main text.

Proof. Consider the following policy: pay out immediately any positive cash reserves, and thereafter keep cash holdings at $s_{t}=0$ by immediately paying out any incoming cash. This leads to forced exit as soon as $x_{t} \leq c$. The unique value function that 
satisfies the appropriate differential equation (equation (2) in the main text) together with the boundary condition $\underline{V}(c)=0$ is given by (34). Since this policy is feasible, it gives a lower bound for the value of the optimally managed firm. On the other hand, the net value of a firm that faces no liquidity constraint is $V^{*}(x)$, and this must be an upper bound for the liquidity constrained firm.

Finally, Lemma 3 states that a firm that is at the edge of being profitable $\left(x_{t}=c\right)$ is more valuable to its owners than its cash holdings. This lemma guarantees that positive cash holdings are optimal at least under some conditions:

Lemma $3 V(c, s)>s$ for all $s>0$.

Proof. The key to this result is the kink in the value function $\underline{V}(x)$ at $x=c$. Take an arbitrary $s>0$, and let $x_{t}=c, s_{t}=s$. Take a sequence $\left\{\Delta_{n}\right\}_{n=1}^{\infty}$ such that $\lim _{n \rightarrow \infty} \Delta_{n}=0$ and $\Delta_{n}>0$ for each $n$. Denote by $V_{n}$ the expected payoff of a feasible (but suboptimal) policy, according to which the firm continues without paying dividends for a period of length $\Delta_{n}$, and thereafter pays out all incoming cash: ${ }^{20}$

$$
V_{n}=e^{-\rho \Delta_{n}} \mathbb{E}\left(\underline{V}\left(x_{t+\Delta_{n}}\right)+s_{t+\Delta_{n}}\right) .
$$

Since $x_{t}$ is a geometric Brownian motion, we have:

$$
\frac{x_{t+\Delta_{n}}-x_{t}}{x_{t}} \sim \mathcal{N}\left(\mu x_{t} \Delta_{n}, \sigma^{2} \Delta_{n}\right) .
$$

Standard properties of Normal distribution imply:

$$
\mathbb{E}\left|\frac{x_{t+\Delta_{n}}-x_{t}}{x_{t}}-\mu x_{t} \Delta_{n}\right|=\sqrt{\frac{2}{\pi}} \sigma \sqrt{\Delta_{n}} .
$$

Since Normal distribution is symmetric around its mean, we have

$$
\mathbb{E}\left[\max \left(0 ; \frac{x_{t+\Delta_{n}}-x_{t}}{x_{t}}-\mu x_{t} \Delta_{n}\right)\right]=\frac{1}{2} \mathbb{E}\left|\frac{x_{t+\Delta_{n}}-x_{t}}{x_{t}}-\mu x_{t} \Delta_{n}\right|=\sigma \sqrt{\frac{\Delta_{n}}{2 \pi}}
$$

so that

$$
\mathbb{E}\left[\max \left(0 ; x_{t+\Delta_{n}}-x_{t}\right)\right]=\frac{\sigma x_{t}}{\sqrt{2 \pi}} \sqrt{\Delta_{n}}+o\left(\Delta_{n}\right),
$$

\footnotetext{
${ }^{20}$ Note that $s_{t}>0$ and $x_{t}-c=0$, so that the firm is not under threat of immediate forced exit. Therefore, as we consider short intervals $\Delta_{n}$, we can safely ignore the possibility that $s_{t^{\prime}}=0$ for some $t^{\prime} \in\left[0, \Delta_{n}\right]$.
} 
where $o\left(\Delta_{n}\right)$ denotes terms that go to zero at least linearly in $\Delta_{n}$. Denoting by $\zeta$ the derivative from right of $\underline{V}(x)$ at the kink:

$$
\zeta:=\lim _{x \downarrow c} \underline{V}(x)>0,
$$

and noting that

$$
\mathbb{E} s_{t+\Delta_{n}}=s_{t}+\mathbb{E} \int_{t^{\prime}=t}^{t+\Delta_{n}}\left(x_{t^{\prime}}-c+r s_{t^{\prime}}\right) d t^{\prime}=s_{t}+o\left(\Delta_{n}\right),
$$

we have

$$
\begin{aligned}
V_{n} & =e^{-\rho \Delta_{n}} \mathbb{E}\left(\underline{V}\left(x_{t+\Delta_{n}}\right)+s_{t+\Delta_{n}}\right) \\
& =e^{-\rho \Delta_{n}}\left(\max \left(0 ; \zeta \frac{\sigma x_{t}}{\sqrt{2 \pi}} \sqrt{\Delta_{n}}\right)+s_{t}+o\left(\Delta_{n}\right)\right) \\
& =\zeta \frac{\sigma x_{t}}{\sqrt{2 \pi}} \sqrt{\Delta_{n}}+s_{t}+o\left(\Delta_{n}\right) .
\end{aligned}
$$

Therefore, for $n$ large enough, $V_{n}>s_{t}$. But since the optimal policy is at least weakly better than this strategy, we have $V\left(c, s_{t}\right) \geq V_{n}$ for any $n$, and it follows that

$$
V\left(c, s_{t}\right)>s_{t}
$$

\section{Proof of Proposition 1}

Part 1: We want to show that there is some $x^{\prime}>x^{*}$ such that stopping is optimal for all $x \leq x^{\prime}, s \geq 0$. Suppose the contrary. Then we can find a sequence $\left\{x_{n}, s_{n}\right\}_{n=1}^{\infty}$ with $x_{n}>x^{*}$ for all $n, \lim _{n \rightarrow \infty} s_{n}=\underline{s}>0$ and $\lim _{n \rightarrow \infty} x_{n}=x^{*}$, such that all points $\left(x_{n}, s_{n}\right)$ are within the continuation region so that (32) holds by Lemma $1 .{ }^{21}$ Since $V^{*}\left(x^{*}\right)=0$, it follows from Lemma 2 that $V\left(x^{*}, s\right)=s$ for all $s$. Therefore

$$
\begin{aligned}
V\left(x_{n}, s_{n}\right) & \rightarrow s_{n} \text { and } \\
V_{s}\left(x_{n}, s_{n}\right) & \rightarrow 1
\end{aligned}
$$

as $n \rightarrow \infty$. By the smooth-pasting condition of the unconstrained firm, we have $V_{x}^{*}\left(x^{*}\right)=0$, and therefore we must have

$$
V_{x}\left(x_{n}, s_{n}\right) \rightarrow 0
$$

\footnotetext{
${ }^{21}$ Part 2 of the Proposition, which we will prove shortly, states that it is optimal to exit whenever $s$ is small enough for all $x<c$, and therefore we can assume a limit point $\underline{s}>0$ for $s_{n}$.
} 
(Otherwise we would have either $V\left(x_{n}, s_{n}\right)<s_{n}$ or $V\left(x_{n}, s_{n}\right)>V^{*}\left(x_{n}\right)+s_{n}$ for $n$ large enough, hence violating Lemma 2.)

Since (32) must hold at all points in the sequence $\left\{x_{n}, s_{n}\right\}_{n=1}^{\infty}$, we have:

$$
\frac{\sigma^{2}}{2} x_{n}^{2} V_{x x}\left(x_{n}, s_{n}\right) \rightarrow(\rho-r) \underline{s}+c-x^{*} .
$$

On the other hand, from the corresponding Hamilton-Jacobi-Bellman equation of the unconstrained firm (equation (2) in the main paper) we have

$$
\frac{\sigma^{2}}{2} x^{2} V_{x x}^{*}\left(x^{*}\right)=c-x^{*}<(\rho-r) \underline{s}+c-x^{*},
$$

and therefore

$$
\lim _{n \rightarrow \infty} V_{x x}\left(x_{n}, s_{n}\right)>V_{x x}^{*}\left(x^{*}\right) .
$$

But since $V\left(x_{n}, s_{n}\right) \rightarrow V^{*}\left(x^{*}\right)+s_{n}$ and $V_{x}\left(x_{n}, s_{n}\right) \rightarrow V_{x}^{*}\left(x^{*}\right)$, this implies that $V\left(x_{n}, s_{n}\right)>V^{*}\left(x_{n}\right)+s_{n}$ for $n$ large enough. This is a contradiction with Lemma 2. We can conclude that $V(x, s)=s$ for all $s$ for some $x>x^{*}$. We let

$$
x_{\min }:=\sup \{x \mid V(x, s)=s \text { for all } s \geq 0\} .
$$

Part 2: By Lemma 3, we have $V(c, s)>s$ for all $s>0$. It follows from continuity of the value function that $V\left(c-\varepsilon, s_{t}\right)>s_{t}$ for some $\varepsilon>0$, so that $x_{\min }$ defined in (35) satisfies $x_{\min }<c$.

Next, we show that for all $x \in\left(x_{\min }, c\right)$, there is some $s^{\prime}>0$ such that $V(x, s)=s$ for all $s \leq s^{\prime}$. Suppose, by contrast, that there is some $x^{\prime} \in\left(x_{\min }, c\right)$ such that $V\left(x^{\prime}, s\right)>s$ for all $s>0$. Since $V(x, s)$ is increasing in $x$, this implies that $V(x, s)>$ $s$ for all $x \in\left(x^{\prime}, c\right), s>0$. Therefore, there is a continuation region that reaches all the way down to $s=0$ for the interval $\left(x^{\prime}, c\right)$, and by Lemma 1, (32) must hold for all $s$ sufficiently small. However, since a cashless firm is forced to exit at $s=0$ for $x<c$, the boundary condition $V(x, 0)=0$ must hold for the whole interval, and therefore also $V_{x}(x, 0)=V_{x x}(x, 0)=0$ for all $x \in\left(x^{\prime}, c\right)$. Substituting these into (32) yields $V_{s}(x, 0)=0$ for $x \in\left(x^{\prime}, c\right)$. But since $V(x, s) \geq s$ for all $(x, s)$ by Lemma 1 , this is a contradiction. It follows that $V(x, s)=s$ for all $x \in\left(x_{\min }, c\right)$ and for all $s \leq s^{\prime}$ for some $s^{\prime}>0$. Define for all $x \in\left(x_{\min }, c\right)$ :

$$
\widetilde{s}(x):=\max \{s \mid V(x, s)=s\} .
$$


It remains to show that $\widetilde{s}\left(x_{t}\right)$ is decreasing in $x_{t}$ and $\lim _{x_{t} \rightarrow c} \widetilde{s}\left(x_{t}\right)=0$. The former property follows from the monotonicity of $V(x, s)$ in $x$ : suppose on the contrary that $\widetilde{s}\left(x^{\prime \prime}\right)>\widetilde{s}\left(x^{\prime}\right)$ for some $x^{\prime \prime}>x^{\prime}$. But then, $V\left(x^{\prime}, \widetilde{s}\left(x^{\prime \prime}\right)\right)>s=V\left(x^{\prime \prime}, \widetilde{s}\left(x^{\prime \prime}\right)\right)$ which violates the property that $V(x, s)$ is increasing in $x$. The latter property follows from the continuity of $V(x, s)$ : suppose that there is some $s^{\prime}>0$ such that $\widetilde{s}(x)>s^{\prime}$ for all $x$ in some open neighborhood of $c$. But this means that $V(x, s)=s$ for all $0<s<s^{\prime}$ when $x$ is arbitrarily close to $c$, and this is in contradiction with continuity of $V(x, s)$ and our previous finding that $V(c, s)>s$ for all $s>0$.

Part 3: One available (non-optimal) policy is to pay-out all incoming cash and keep cash balance at $s_{t}=0$. When $x>c$, this policy gives value $\underline{V}(x)+s>s$, so it cannot be optimal to exit.

Part 4: Fix $s>0$, and suppose that it is not optimal to pay dividends even at high values of $x$ so that (32) holds for all $x$. Let $x \rightarrow \infty$. From equation (5) in the main text and $(34), V^{*}(x)-\underline{V}(x) \rightarrow 0$, and therefore it follows from Lemma 2 that $V(x, s) \rightarrow V^{*}(x)+s$. This means that $V_{s}(x, s) \rightarrow 1, V_{x}(x, s) \rightarrow V_{x}^{*}(x)$, and $V_{x x}(x, s) \rightarrow V_{x x}^{*}(x)$, so that

$$
\rho V(x, s)-\mu x V_{x}(x, s)-\frac{\sigma^{2}}{2} x^{2} V_{x x}(x, s) \rightarrow \rho\left(V^{*}(x)+s\right)-\mu x V_{x}^{*}(x)-\frac{\sigma^{2}}{2} x^{2} V_{x x}^{*}(x) .
$$

But then, combining (32) and equation (2) in the main text,

$$
r s \rightarrow \rho s,
$$

which is a contradiction because we have $\rho>r$ and $s>0$. It follows that the continuation region must be bounded from the right: it is optimal to pay dividends for high enough $x$. We let

$$
x_{\max }:=\inf \{x>c \mid V(x, s)=V(x, 0)+s \text { for all } s \geq 0\} .
$$

Finally, fix $x>x_{\min }$ and suppose that it is not optimal to pay dividends even at high values of $s$. But then, as $s \rightarrow \infty$, it follows from (32) that

$$
\mu x V_{x}(x, s)+\frac{\sigma^{2}}{2} x^{2} V_{x x}(x, s) \rightarrow \infty .
$$

But this is in contradiction with (33) holding for all $x$ and $s$, and the fact that $V_{x}^{*}(x)$, $V_{x x}^{*}(x), \underline{V}_{x}(x)$, and $\underline{V}_{x x}(x)$ are all bounded and independent of $s$. We can therefore conclude that the continuation region must be bounded from above: it is optimal to pay dividends for high enough $s$. We let

$$
s_{\max }:=\inf \left\{s>0 \mid V\left(x, s^{\prime}\right)=V(x, s)+s^{\prime}-s \text { for all } x \text { and for all } s^{\prime} \geq s\right\} .
$$




\section{Appendix B: Stationary distributions}

\section{Unconstrained Case}

In the unconstrained case, the steady-state firm distribution and its properties reported in Section 4 can be derived analytically as follows. Denote $y \equiv \log z$. The exit threshold is $y^{*}=\log z^{*}$ and new firms are born at $y_{0}>y^{*}$. Taking a discrete time approximation, $y$ follows the binomial process:

$$
y(t+\Delta)=\left\{\begin{array}{l}
y(t)+\Delta y \quad \text { with probability } q \\
y(t)-\Delta y \quad \text { with probability } 1-q
\end{array}\right.
$$

where $\Delta$ is the length of a period, $q=\frac{1}{2}\left(1+\frac{\mu-\sigma^{2} / 2}{\sigma} \sqrt{\Delta}\right)$, and $\Delta y=\sigma \sqrt{\Delta}$. The steady state condition gives a difference equation for the mass of firms located at an arbitrary state point $y$,

$$
(1-\lambda \Delta)[q f(y-\Delta y)+(1-q) f(y+\Delta y)] \Delta y+g(y) \Delta y=f(y) \Delta y
$$

where $f(y) \Delta y$ is the mass of all firms and $g(y) \Delta y$ is the mass of newborn firms at state point $y$. Taking the limit $\Delta \rightarrow 0$ leads to a differential equation for the stationary firm density: ${ }^{22}$

$$
\frac{1}{2} \sigma^{2} f^{\prime \prime}(y)-\left(\mu-(1 / 2) \sigma^{2}\right) f^{\prime}(y)-\lambda f(y)+g(y)=0
$$

with $f\left(y^{*}\right)=0$ and $\lim _{y \rightarrow \infty} f(y)=0$ as boundary conditions. In our setup $g(y)$ is positive at $y_{0}$ and zero elsewhere. The point $y_{0}$ splices the differential equation into two regions, with the $f\left(y_{0}\right)=f_{0}$ as a boundary condition in the middle. ( $f$ is finite but not differentiable at $\left.y_{0}\right)$. The value of $f_{0}$ can be solved from the condition that total probability density integrates to one. Combining the boundary conditions with (36) yields the closed-form solution:

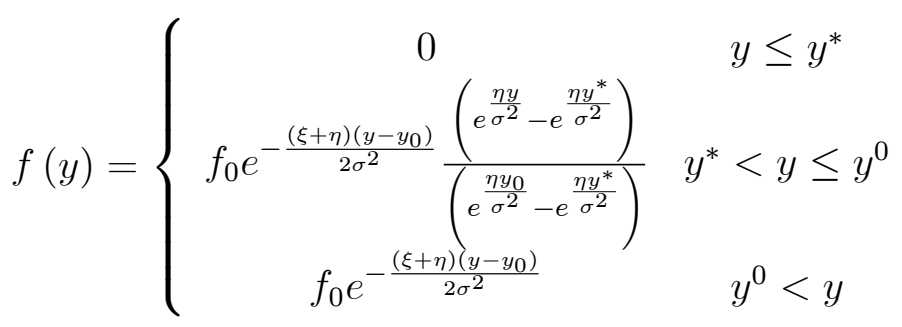

\footnotetext{
${ }^{22}$ See Dixit and Pindyck (1993), chapter 8, section 4.c for more details.
} 
where $\xi \equiv \sigma^{2}-2 \mu, \eta=\sqrt{8 \lambda \sigma^{2}+\xi^{2}}$, and

$$
f_{0}=\frac{2 \lambda}{\eta} \frac{\left(e^{\frac{\eta y_{0}}{\sigma^{2}}}-e^{\frac{\eta y^{*}}{\sigma^{2}}}\right)}{\left(e^{\frac{\eta y_{0}}{\sigma^{2}}}-e^{\frac{(\eta-\xi) y^{*}+(\eta+\xi) y_{0}}{2 \sigma^{2}}}\right)} .
$$

There is no economically sensible steady state unless $z=e^{y}$ has a finite mean. Here $\int_{y_{0}}^{\infty} e^{y} f(y) d y<\infty$ is a necessary and a sufficient condition for the finite mean. Taking out the terms that are independent of $y$ in (37), the finite mean requirement becomes

$$
\int_{y_{0}}^{\infty} e^{y-\frac{(\xi+\eta) y}{2 \sigma^{2}}} d y<\infty .
$$

This holds if $2 \sigma^{2}-\xi-\eta<0$, which simplifies to $\lambda>\mu$.

\section{Constrained Case}

The stationarity proof in the unconstrained case is sufficient for the stationarity of the distribution of $z$ in the constrained process. As $s$ is endogenously bounded by the optimal dividend policy and, firm by firm, depends deterministically on the history of $z$, the fact that $z$ has a stationary distribution suffices for the stationarity of the joint distribution $(z, s)$. However, now the optimal policy has no closed-form solution so the steady state distribution must be computed numerically. In the discrete time approximation the life span of each individual firm is a Markov chain in the discretized state space. Therefore, the steady state distribution is obtained by first computing the optimal policy of an individual firm, and then, starting from some initial firm distribution, iterating the firm distribution according to the state transition equations associated with the policy (where a constant mass of new firms are established at the birth point within each iteration) until the firm distribution converges to the steady state.

\section{References}

Albuquerque, Rui and Hugo Hopenhayn (2004): "Optimal Lending Contracts and Firm Dynamics." Review of Economic Studies, 71, pp. 285-315.

Boyle, Glenn W and Graeme A Guthrie (2003): "Investment, Uncertainty, and Liquidity." Journal of Finance, 58, pp. 2143-2166. 
Caballero, Ricardo and Robert Pindyck (1996): "Uncertainty, Investment, and Industry Evolution." International Economic Review, 37, pp. 641-662.

Cooley, Thomas F and Vincenzo Quadrini (2001): "Financial Markets and Firm Dynamics." American Economic Review, 91(5), pp. 1286-1310.

Cox, John D; Stephen A Ross and Mark Rubinstein (1979): "Option Pricing: A Simplified Approach." Journal of Financial Economics, 97, pp. 229-263.

Deaton, Angus (1991): "Saving and Liquidity Constraints." Econometrica, 59, pp. 1221-1248.

Décamps, Jean-Paul and Stéphane Villeneuve (2007), "Optimal Dividend Policy and Growth Option." Finance and Stochastics, 11, pp. 3-27.

Décamps, Jean-Paul; Thomas Mariotti; Jean-Charles Rochet and Stéphane Villeneuve (2011), "Free Cash-Flow, Issuance Costs and Stock Price Volatility." Journal of Finance, 66, pp. 1501-1544.

Demarzo, Peter M and Yuliy Sannikov (2006): "Optimal Security Design and Dynamic Capital Structure in a Continuous-Time Agency Model." Journal of Finance, 61, pp. 2681-2724.

Demarzo, Peter M And Yuliy Sannikov (2008): "Learning in Dynamic Incentive Contracts." Unpublished paper.

Dixit, Avinash (1989): "Entry and Exit Decisions under Uncertainty." Journal of Political Economy, 97, pp. 620-638.

Dixit, Avinash and Robert Pindyck (1994): "Investment Under Uncertainty." Princeton University Press, Princeton NJ.

Dumas, Bernard (1991): "Super Contact and Related Optimality Conditions." Journal of Economic Dynamics and Control, 15, pp. 675-685.

Dutta, Prajit K and Roy Radner (1999): "Profit Maximization and the Market Selection Hypothesis." Review of Economic Studies, 66, pp. 769-798.

Evans, David S And Boyan Jovanovic (1989): "An Estimated Model of Entrepreneurial Choice under Liquidity Constraints." Journal of Political Economy, 97(4), pp. $808-27$.

Gomes, Joao F (2001): "Financing Investment." American Economic Review, 91(5), pp. $1263-1285$.

Gryglewicz, Sebastian (2011): "A Theory of Financial Decisions with Liquidity and Solvency Concerns." Journal of Financial Economics, 99, pp. 365-384.

Hennessy, Christopher A and Toni A Whited (2007): "How Costly is External 
Financing? Evidence from a Structural Estimation." Journal of Finance, 62, pp. $1705-1745$.

Holmström, Bengt and Jean Tirole (2011): Inside and Outside Liquidity." MIT Press.

Holtz-Eakin, Douglas; David Joulfaian and Harvey S Rosen (1994): "Sticking It Out: Entrepreneurial Survival and Liquidity Constraints." Journal of Political Economy, 102(1): pp. 53-75.

Hopenhayn, Hugo (1992): "Entry, Exit, and Firm Dynamics in Long Run Equilibrium." Econometrica, 60, pp. 1127-1150.

Jones, John B (2003): "The Dynamic Effects of Firm-Level Borrowing Constraints." Journal of Money, Credit, and Banking, 35(5), pp. 743-762.

McDonald, Robert and Daniel Siegel (1986): "The Value of Waiting to Invest." Quarterly Journal of Economics, 101(4), pp. 707-728.

Mello, Antonio S and John E Parsons (2000): "Hedging and Liquidity." Review of Financial Studies, 13, pp. 127-153.

Miao, Jianjun (2005): "Optimal Capital Structure and Industry Dynamics." Journal of Finance, 60, pp. 2621-2659.

Milne, Alistair and Donald Robertson (1996): "Firm Bahviour under the Threat of Liquidation." Journal of Economic Dynamics and Control, 20, pp. 14271449.

Murto, Pauli and Marko Terviö (2010): "Exit Options and Dividend Policy under Liquidity Constraints." HECER Discussion Paper 254.

Peura, Samu and Jussi Keppo (2006): "Optimal Bank Capital with Costly Recapitalization." Journal of Business, 79, pp. 2163-2201.

Radner, Roy and Larry Shepp (1996): "Risk vs Profit Potential: A Model For Corporate Strategy." Journal of Economic Dynamics and Control, 20, pp. 1373-1393. Rochet, Jean-Charles and Stéphane Villeneuve (2005): "Corporate Portfolio Management." Annals of Finance, 1, pp. 225-243.

Zeldes, Stephen P (1989): "Optimal Consumption with Stochastic Income: Deviations from Certainty Equivalence." Quarterly Journal of Economics, 104(2), pp. $275-298$.

Zingales, Luigi (1998): "Survival of the Fittest or the Fattest? Exit and Financing in the Trucking Industry." Journal of Finance, 53(3), 905-38. 